Research Article

\title{
Stability Analysis of TBM Tunnel Undercrossing Existing High-Speed Railway Tunnel: A Case Study from Yangtaishan Tunnel of Shenzhen Metro Line 6
}

\author{
Mingji Zhao $\mathbb{D}^{1},{ }^{1}$ Yun Cheng $\mathbb{D},^{2,3}$ Zhanping Song $\mathbb{D}^{2,3}$ Tong Wang $\mathbb{D}^{2,3}$ Yuwei Zhang, ${ }^{2,3}$ \\ Yitong Gong, ${ }^{2}$ and Yuncai Song ${ }^{4}$ \\ ${ }^{1}$ School of Mechanical and Electrical Engineering, Xi'an University of Architecture and Technology, Xi'an 710055, China \\ ${ }^{2}$ School of Civil Engineering, Xi'an University of Architecture and Technology, Xi'an 710055, China \\ ${ }^{3}$ Shaanxi Key Laboratory of Geotechnical and Underground Space Engineering, Xi'an 710055, China \\ ${ }^{4}$ China Railway Construction Bridge Engineering Bureau Group Co., Ltd., Tianjin 300300, China
}

Correspondence should be addressed to Yun Cheng; chengyun_ifu@163.com and Zhanping Song; songzhpyt@xauat.edu.cn

Received 13 November 2020; Revised 11 December 2020; Accepted 24 December 2020; Published 16 January 2021

Academic Editor: Xingzhou Chen

Copyright (C) 2021 Mingji Zhao et al. This is an open access article distributed under the Creative Commons Attribution License, which permits unrestricted use, distribution, and reproduction in any medium, provided the original work is properly cited.

During the construction of the underpass of a new tunnel, the excavation unloading effect disturbs surrounding rock masses and promotes surrounding rock deformation, inevitably changing stress and displacement in the existing tunnel. Taking Yangtaishan tunnel excavation of Shenzhen Metro Line 6 as an engineering example, effects of excavation programs of left and right lines on the deformation characteristics of newly excavated and existing tunnels were evaluated based on Midas numerical model and priority excavation advantages of the left line were determined. The settlement and horizontal deformation characteristics of the existing tunnel were analyzed using the construction monitoring method. Results showed that maximum settlement and horizontal deformation of the existing tunnel were 1.35 and $0.23 \mathrm{~mm}$, respectively. Settlement of invert and inverted top along axis direction was from growth to decline, and then a $\mathrm{V}$-shaped settlement trough was formed with maximum settlement values of 1.36 and $0.97 \mathrm{~mm}$, respectively. Maximum settlement and uplift of the newly built tunnel appeared on the upper and bottom parts of invert, respectively. In the newly built tunnel segments, the top settlement was dominated and deformation was mainly distributed in both side areas. At the top of the existing tunnel segment, convergence settlement was $3.09 \mathrm{~mm}$ and settlement rate was slow first which was accelerated, then stabilized, and finally slowed down again which was opposite to the uplift development trend of the bottom of tunnel segment. The top of the existing tunnel segment showed four settlement stages, slow, rapid, stable, and slow settlement stages. Compared with the right line, preferential excavation of the left line had obvious advantages in terms of tunnel stability. The unloading effect of TBM excavation created vault settlement in the existing tunnels where actual settlement values were 1.12 and 1.13 times, which theoretically calculated settlement. The horizontal deformation of the existing tunnel was varied first linearly and then nonlinearly with maximum deformation in the convergence stage of $1.47 \mathrm{~mm}$.

\section{Introduction}

Keeping in mind that the transportation infrastructure of China has been rapidly developed during the past 20 years, the construction processes of railways, highways, and subways are no longer similar to what they were before: only consider its own construction conditions and not close to other projects [1-6]. In particular, in urban underground space engineering practices, new tunnels would inevitably underpass the existing buildings and important traffic lines. Therefore, the excavation of new tunnels disturbs the strata surrounding tunnel body and even affects the safe use of adjacent existing buildings [7-10]. When a new underground rock mass project is executed near a high-speed railway tunnel, which poses unprecedented challenges to the safe construction of underpass [11-16], strict requirements are imposed on the settlement and deformation of surrounding rocks due to the existing high-speed railway line [17-19]. 
During the construction of the underpass of a new tunnel, the excavation unloading effect disturbs surrounding rock masses and promotes surrounding rock deformation $[4,5,8]$, inevitably changing stress and displacement in the existing tunnel. Such engineering problems has continuously attracted the attention of a great number of engineers and researchers around the world [20, 21]. For example, adopting the tunnel project between Pudongnan Station and Nanpu Bridge Station as a case study, Shen et al. [22] investigated the changes of segment displacement and ground settlement when the first and following tunnels were constructed horizontally and vertically. Lei [23] simulated the Guantouling Tunnel of Wen-Fu Railway underneath the highway tunnel and determined its excavation geometry. Zhao et al. [24, 25] applied Flac software for the simulation of the construction of a TBM tunnel underpassing a culvert and calculated stress and deformation values. Lai et al. [26] investigated the construction of the existing tunnel with a small angle inclined underpass and evaluated the influences of the pressure and quantity of grouting on the existing tunnel structure and track. Zhang et al. [27] and Huo et al. [28] simulated different tunnel underpass construction methods, especially TBM construction methods, using numerical simulation software. Moreover, Song et al. [29], and Wang et al. [30] studied different factors such as ground deformation law along tunnel direction, characteristic parameters of surface settlement trough, and tunnel segment deformation in urban rail engineering. Lunardi and Cassani [31] studied the influences of various reinforcement measures and tunnel excavation methods on the deformation of the existing high-speed railways in Italy. Sharma et al. [32] evaluated the effect of the lining stiffness of the existing tunnel on structural deformation.

In this work, the TBM excavation of Yangtaishan tunnel on the section between Dalang and Shiyan stations of Shenzhen Metro Line 6 has been studied as an engineering case study. The effects of the excavation programs of the left and right lines of newly built Shenzhen Metro Line 6 on the deformation characteristics of the existing tunnel Guangzhou-Shenzhen-Hong Kong high-speed railway tunnel were investigated by using Midas/NX numerical software, and the construction advantages of priority excavation on the left line of the newly built tunnel were determined. Then, the influences of the excavation unloading effect of the left line tunnel on the settlement and horizontal deformation properties were evaluated by construction monitoring. We hope that the results reported in this work provide a reference for the construction of double-shield TBM underpassing the existing tunnels in shallow-buried composite strata.

\section{Engineering Overview}

2.1. Engineering Background. Shenzhen Metro Line 6 is an urban express line which connects Shenzhen North Station with Futian Central District. The tunnel is distributed in a "7-shaped" pattern, passing through the three Longhua, Guangming, and Bao'an administrative districts. This line has 20 stations and the total length of it is $37.60 \mathrm{~km}$.
Yangtaishan tunnel is located on the interval line between Dalang and Shiyan stations of Shenzhen Metro Line 6. It mainly adopts the combination of undercut and TBM constructions; the starting and ending mileages of the tunnel were YDK $24+160$ and YDK $27+453.35$, respectively. The total length of the path was $3293.35 \mathrm{~m}$ where the lengths of open excavation, undercut, TBM construction, and ventilation shaft sections were 425 603, 2037 (accounting for $61.85 \%$ of the total length of Yangtaishan tunnel), and $98 \mathrm{~m}$, respectively, and the length of tunnel mixing station was $26.10 \mathrm{~m}$. Excavation diameter, segment thickness, and clear distance between the left and right tunnels of Yangtaishan tunnel were $6.20,40$, and $6.80 \mathrm{~m}$, respectively.

The existing tunnel constructed in 2005 is a single-hole, double-track, horseshoe-shaped tunnel with a cross-section width and height of 14.40 and $12.18 \mathrm{~m}$, respectively. The primary supporting consists of $0.15 \mathrm{~m}$ thick C25 sprayed concrete and the secondary lining is C30 concrete with $0.40 \mathrm{~m}$ thickness. The buried depth of the inverted top of the tunnel is about $95 \mathrm{~m}$ and is located in slightly weathered granite. Yangtaishan tunnel underpasses the existing tunnel at YDK25+892 with spatial cross angle and vertical net spacing of about 25 and $30.07 \mathrm{~m}$, respectively. Therefore, the main aim of this paper was to evaluate the influence of double-shield TBM tunneling construction on the stability of the existing tunnel. Shenzhen Metro Line 6 with tunnel underpass section and the cross section of the existing tunnel are shown in Figures 1(a) and 1(b), respectively.

2.2. Engineering Geological Characteristics. Geological surveys showed that an $F_{2}$ fault was developed in Yanshanian granite near section YDK24 + 710 (tunnel entrance section) of Yangtaishan tunnel, which belongs to Huangcaokeng top fault (paddy field fault). Fault trend, inclination angle, and fracture zone length and width were about $310 \sim 330^{\circ}, 50 \sim 70^{\circ}$, $14 \mathrm{~km}$, and $3 \sim 7 \mathrm{~m}$, respectively. A secondary $F_{2-2}$ fault was also detected near YDK25+825 section by combining drilling and magnetotelluric survey data, which could be created under the effect of $F_{2}$ fault. Joints were relatively developed, core breaking degree was larger, strength was relatively low (uniaxial compressive strength in the saturated state was $15 \sim 40 \mathrm{MPa}$ ), and the permeability was good (permeability coefficient was $2 \sim 5 \mathrm{~m} / \mathrm{d}$ ). Figure 2 shows the geological distribution map of the undercrossed section as well as the drilling cores of $F_{2}$ and $F_{2-2}$ faults.

It was seen from Figure 2(a) that the rock layer from the upper layer to buried depth consisted of granite. Based on weathering degree, this layer could be divided into completely weathered (1), highly weathered (2), including (2)-1 and (2)-2), moderately weathered (3), and weakly weathered (4) regions. $F_{2-2}$ fault had penetrated through four different weathered granite layers. The mechanical parameters of these weathered granite layers are summarized in Table 1. Completely weathered granite was distributed in layers on the weathered layer surface with an average thickness of $8.11 \mathrm{~m}$. Highly weathered granite had a coarsegrained structure with an average thickness of $12.50 \mathrm{~m}$. Moderately weathered granite also had a coarse-grained 


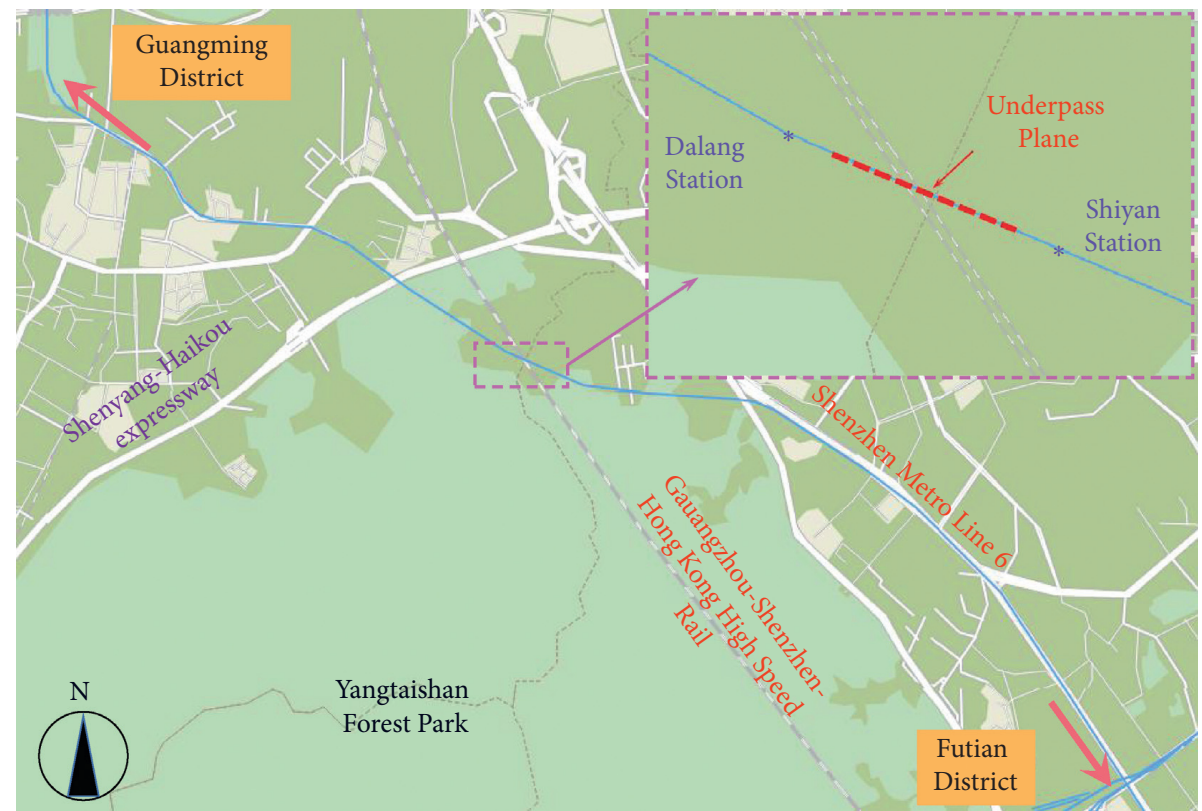

(a)

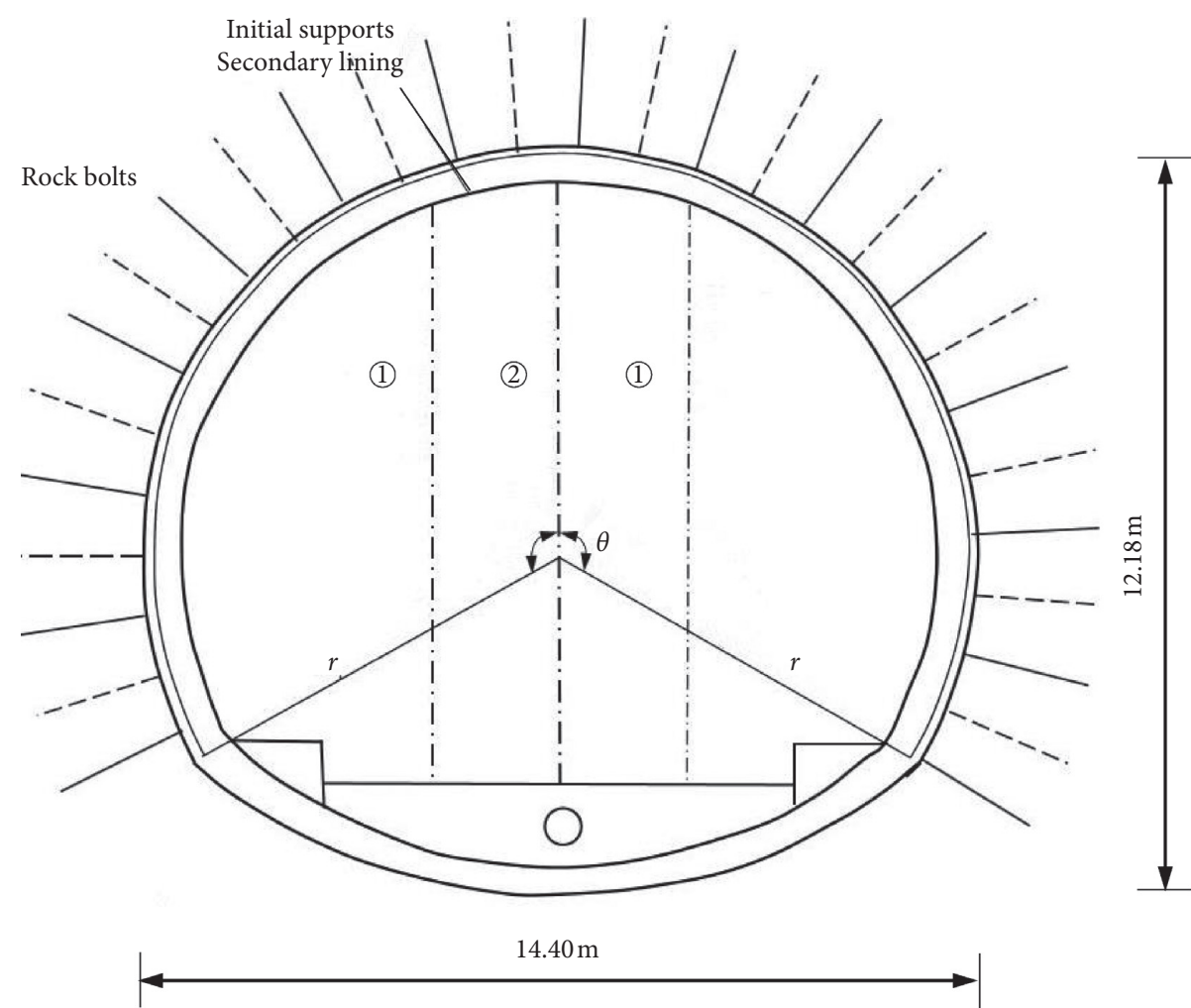

(b)

Figure 1: Direction of Shenzhen Metro Line 6 and section of the existing tunnel. (a) Shenzhen Metro Line 6 and the tunnel underpass section. (b) Cross section of the existing tunnel. Notes: (1) center line of the railway; (2) center line of the tunnel; $r=6.65 \mathrm{~m} ; \theta=108.67^{\circ}$.

structure with a massive structure and well-developed joints. Week weathered granite was a rock layer surrounding the existing and underpass tunnels; it also had coarse-grained structure and large burial depth and featured a massive structure. The vault of the existing tunnel was $95 \mathrm{~m}$ from the top of completely weathered granite and its bottom was $30.74 \mathrm{~m}$ from TBM tunnel vault.
2.3. Hydrogeological Characteristics. The underdeveloped surface water within the construction site of Yangtaishan tunnel was dominated by pond and mountain stream waters. Groundwater was mainly composed of loose rock pore water and bedrock fissure water. Loose rock pore water was mainly distributed in Quaternary loose accumulation layer and Quaternary pore water mainly occurred in site sand and 


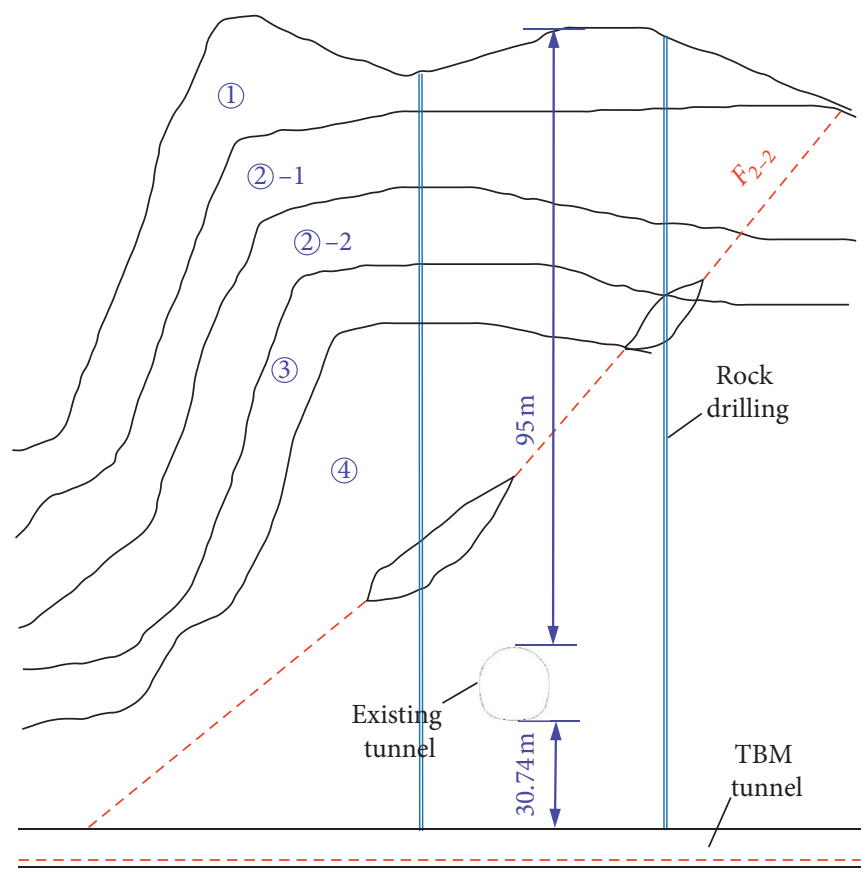

(a)

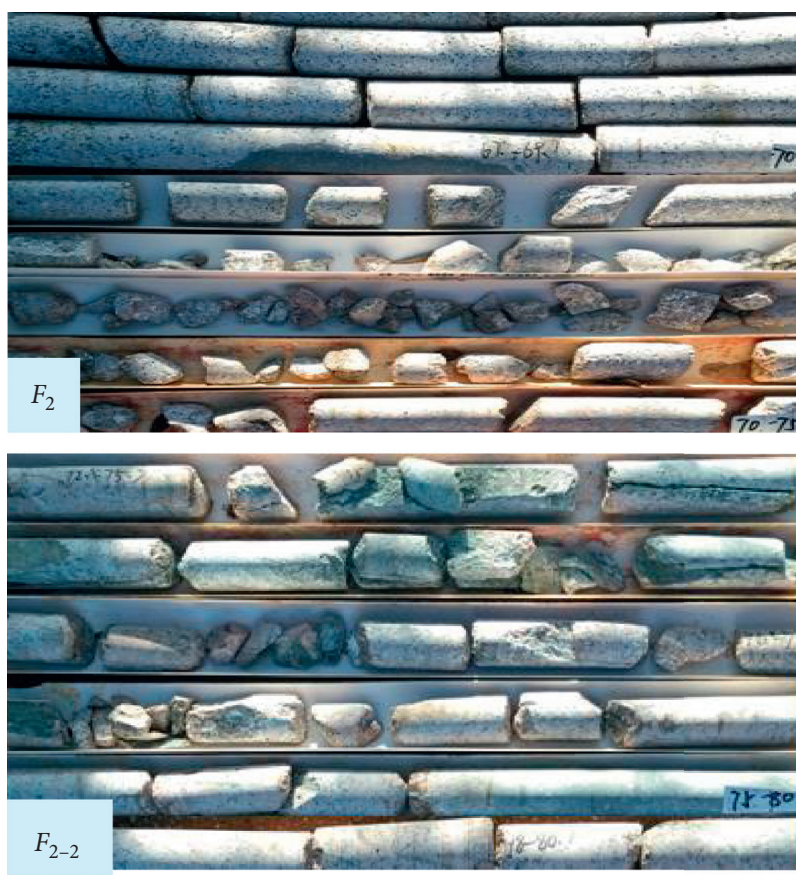

(b)

Figure 2: Geological distribution map of undercross section and drilling cores. (a) Geological distribution map of undercross section. (1) Completely weathered region. (2) Highly weathered region. (3) Moderately weathered region. (4) Week weathered region. (b) Drilling cores of $F_{2}$ and $F_{2-2}$ faults.

Table 1: Physical and mechanical parameters of materials.

\begin{tabular}{|c|c|c|c|c|c|c|}
\hline \multicolumn{2}{|c|}{ Material types } & $\gamma\left(\mathrm{kN} \cdot \mathrm{m}^{-3}\right)$ & $E(\mathrm{MPa})$ & $\mu$ & $\varphi\left(^{\circ}\right)$ & $c(\mathrm{MPa})$ \\
\hline \multirow{5}{*}{ Granite } & Completely weathered region (1) & 9.20 & 4.90 & 0.40 & 23 & 0.02 \\
\hline & Highly weathered region (2)-1 & 11.50 & 50 & 0.33 & 30 & 0.07 \\
\hline & Highly weathered region (2)-2 & 15.60 & 160 & 0.31 & 42 & 0.10 \\
\hline & Moderately weathered region (3) & 20.10 & 5000 & 0.25 & 45 & 20 \\
\hline & Week weathered region (4) & 26.80 & 20000 & 0.22 & 55 & 55 \\
\hline \multicolumn{2}{|c|}{ Fault fracture zone } & 17 & 150 & 0.28 & 37 & 0.09 \\
\hline \multicolumn{2}{|l|}{ Lining } & 25 & 21000 & 0.26 & - & - \\
\hline \multicolumn{2}{|l|}{ Segment } & 25 & 27000 & 0.20 & - & - \\
\hline \multicolumn{2}{|c|}{ TBM shield } & 78 & 250000 & 0.20 & - & - \\
\hline
\end{tabular}

residual layer. Underground water buried depth, average buried depth of groundwater level, and groundwater elevation of the tunnel were $0.70 \sim 42.80 \mathrm{~m}, 7.43 \mathrm{~m}$, and 61.49 161.64 m, respectively. Fracture water Yangtaishan tunnel bedrock had nonuniform characteristic. Since the underlying bedrock in the field consisted of granite, rock mass structure of the region was dense, natural porosity was low, and rock mass itself had poor water permeability. Bedrock fissure water mainly occurred in highly and moderately weathered areas.

\subsection{Numerical Model and Excavation Schemes}

2.4.1. Numerical Model and Parameters. Assuming that ground and each soil layer were homogeneous with horizontal distribution, rock and soil masses followed the
Mohr-Column constitutive model [4] and segments, TBM shells, and existing tunnel lining were modeled by plate elements which constrained the translational degrees of freedom along the horizontal direction on the sides and vertical direction at the bottom of the model. Based on the theory of elasticity and rock mechanics $[21,22]$, the area of the influence of tunnel excavation on the stress state of surrounding rock was 3 4 times the width of the tunnel outside tunnel excavation contour line. The horizontal direction ( $x$-axis) of the developed numerical model was about $109 \mathrm{~m}$, the tunnel axis direction ( $y$-axis) was about $130 \mathrm{~m}$, and the vertical direction ( $z$-axis) was $160 \mathrm{~m}$ from the tunnel bottom to the lower boundary. The numerical model was divided into 142800 units with 25000 nodes. The 3D model of underpass segment is shown in Figure 3 and as can be seen 


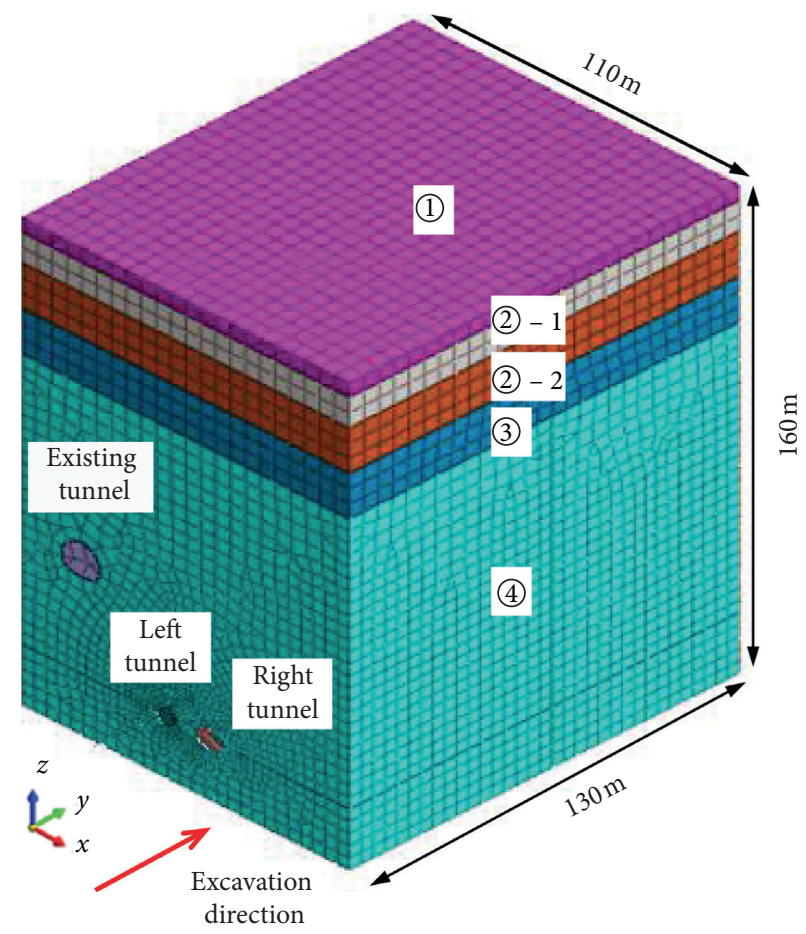

Figure 3: Three-dimensional model of underpass segment.

from the figure, the cross-section dimensions of the existing tunnel in the model were the same as those shown in Figure 1(b).

However, it is noteworthy that the spatial angle between the existing and newly built tunnels was taken into account in the developed model and the distance between the left interface of the model and underpass position (YDK25 + 892) was taken to be about $65 \mathrm{~m}$. The elevations of the left and right lines as well as cross-sectional dimensions were the same and the distance from the bottom of the tunnel to the lower boundary of the model was $17 \mathrm{~m}$. The physical and mechanical properties of granite layer, fault fracture zone, lining, segment, and TBM shield shown in Figure 3 are summarized in Table 1 , where $\gamma, E, \mu, \varphi$, and $c$ are material weight $\left(\mathrm{kN} / \mathrm{m}^{3}\right)$, elastic modulus $(\mathrm{MPa})$, Poisson's ratio, friction angle $\left({ }^{\circ}\right)$, and cohesion $(\mathrm{kPa})$, respectively. Completely weathered (1), highly weathered (2), moderately weathered (3), and weakly weathered (4) regions given in Table 1 correspond to those presented in Figure 3.

2.4.2. TBM Excavation Program. Along with the construction principle of double-shield TBM [24], we have considered the factors influencing TBM shield shell, gravity, and the pressures of tunneling, jacking, and grouting. TBM construction numerical simulation procedure is shown in Figure 4. In this procedure, TBM tunneling pressure $\left(P_{T}\right)$ was $0.30 \mathrm{MPa}$, grouting pressure $\left(P_{G}\right)$ was $0.20 \mathrm{MPa}$, and jacking pressure $\left(P_{J}\right)$ was $200 \mathrm{kN} / \mathrm{m}$ which was applied in as linear loading. The basic assumptions of the simulation were as follows: (1) the influence of groundwater on the stability of surrounding rock after TBM excavation was neglected [27] and (2) hardened grouting area between segment and surrounding rock was replaced by an equivalent layer of $0.15 \mathrm{~m}$ after TBM tunnel excavation [29, 33].

In this paper by assuming that the newly built TBM tunnel was not vertically underneath the existing tunnel (the angle is about $25^{\circ}$ ), we have mainly focused on the influences of different excavation programs of double-line tunnels on deformation characteristics. Two excavation programs were compared as follows.

Program I is as follows:

Step 1. Excavation of the inner rock mass of the left tunnel, addition of the TBM shield shell, and application of excavation face pressure $\left(P_{T}\right)$

Step 2. Installation of tunnel segment and application of jacking pressure $\left(P_{J}\right)$ to segment

Step 3. Application of grouting pressure $\left(P_{G}\right)$ to reinforce and hardening of walls on both sides

Step 4. Repetition of Steps 1 to 3 until the left tunnel was completed

Step 5. The above 4 steps were executed in the same order on the right line of the tunnel until it was completed

Program II: This construction program was basically the same as program I, the only difference being that, in program II, first the right line and then the left line of the tunnel were excavated. In the following two sections, the deformation characteristics of the existing and newly built tunnels have been mainly studied based on the above TBM construction program. 


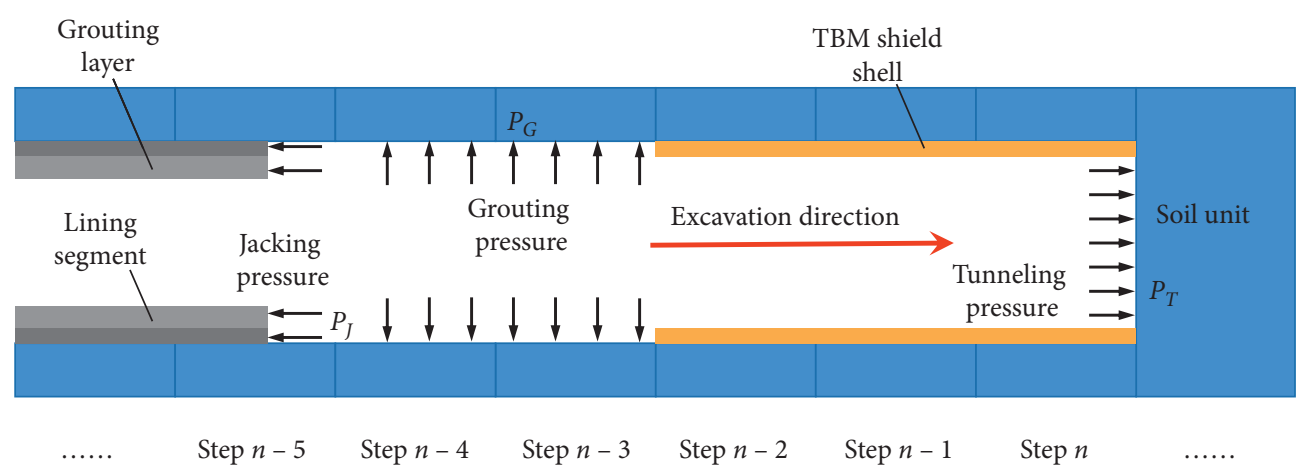

FIGURE 4: Diagram of TBM construction numerical simulation process.

\section{Simulation Results and Analysis}

3.1. Deformation Characteristics of the Existing Tunnel. To investigate the influence of different excavation programs on the deformation characteristics of the existing tunnel, cloud diagram of the vertical settlement of the existing tunnel lining obtained based on numerical simulation results was considered, as shown in Figure 5, where $D$ represents settlement displacement $(\mathrm{mm})$. It was seen from Figure 5 that different excavation programs (described in Section 2.4.2) applied to the left and right lines of the newly built tunnel had basically the same influence on the settlement characteristics of the existing tunnel lining. The vertical settlement displacement of tunnel lining in the central area of the existing tunnel was large with values of about $0.87 \sim 1.04 \mathrm{~mm}$ and $0.65 \sim 1.09 \mathrm{~mm}$, respectively. By getting farther from the center of the tunnel and the decrease of vertical settlement of the existing tunnel lining, settlement values were $0.56 \sim 0.77 \mathrm{~mm}$ and $0.56 \sim 0.59 \mathrm{~mm}$, respectively. The maximum settlement of the existing tunnel lining was $1.35 \mathrm{~mm}$ after the completion of the construction of the underpass section. It was seen that different excavation programs for the double-line tunnel had little effect on the settlement law of the existing tunnel lining. Figure 6 shows the cloud diagram of horizontal displacement of the existing tunnel lining. It was seen from Figure 5 that the maximum horizontal displacement of the existing tunnel lining occurred in front of the central position of the existing tunnel with a maximum deformation value of $0.23 \mathrm{~mm}$. However, horizontal displacement behind the center of the existing tunnel was small with a minimum deformation value of $0.03 \mathrm{~mm}$, which corresponded to about $13.04 \%$ of maximum deformation.

Once TBM construction of the underpass section was completed, the increase of the settlement values of invert and inverted top along axial direction and excavation steps are shown in Figure 7. It was seen that the vertical settlements of invert and inverted top of the existing tunnel were larger at the center of the tunnel. It was also found that vertical settlement was decreased by the increase of distance from the center of the existing tunnel. It was seen from Figure 7 (a) that the vertical settlements of tunnel vault and inverted top were first increased and then decreased by the increase of the length of the existing tunnel. The demarcation point of the two stages was $x=68 \mathrm{~m}$. The settlement of invert was lower than that of vaulted top.

Comparison of the settlement curves of invert and inverted top showed that (a) the vertical settlement values of inverted top were $0.60 \sim 0.86 \mathrm{~mm}$ and $0.57 \sim 0.83 \mathrm{~mm}$ in range of $0 \sim 24 \mathrm{~mm}$ and $120 \sim 148 \mathrm{~m}$ and the corresponding values for invert were $0.77 \sim 0.86 \mathrm{~mm}$ and $0.73 \sim 0.83 \mathrm{~mm}$, respectively. The average settlement values of invert were significantly larger than that of inverted top, such that settlement values for the former were about 1.12 and 1.11 times the corresponding values of the latter. (b) The settlement of invert was significantly greater than that of invert top in the range of $24 \sim 120 \mathrm{~m}$ and the maximum settlement of invert $(1.36 \mathrm{~mm})$ was 1.40 times that of inverted top $(0.97 \mathrm{~mm})$. (c) The settlement curves of the invert and inverted top of the existing tunnel presented a $\mathrm{V}$-shaped (settling trough) distribution characteristic which was consistent with the findings of Niu et al. [34]. The settlements of invert and inverted top were in a quadratic function with increasing axial distance.

By assigning top priority to the excavation of the left tunnel as a research object, Figure 7 (b) shows the settlement variation curves of invert and inverted top of the central section (a characteristic section) of the existing tunnel with increasing excavation step. It was seen from Figure 7(b) that the vertical settlement curve of the existing tunnel invert first showed a rapid increase, then a gentle development, and finally a sharp increase. The demarcation points of the three stages were the excavation face of left and right lines. Compared with invert settlement, vertical settlement curve of inverted top tended to increase slowly; there was no obvious stabilization stage, and settlement amount of inverted top was increased almost linearly.

The settlement data presented in Figure 7(b) show that when the excavation step of the left line was less than 24 , the development path of the vertical settlement curves of invert and inverted top of the existing tunnel was almost coincident. The settlement values of invert and inverted top were $0.31 \mathrm{~mm}$ and $0.23 \mathrm{~mm}$, respectively, the settlement growth 


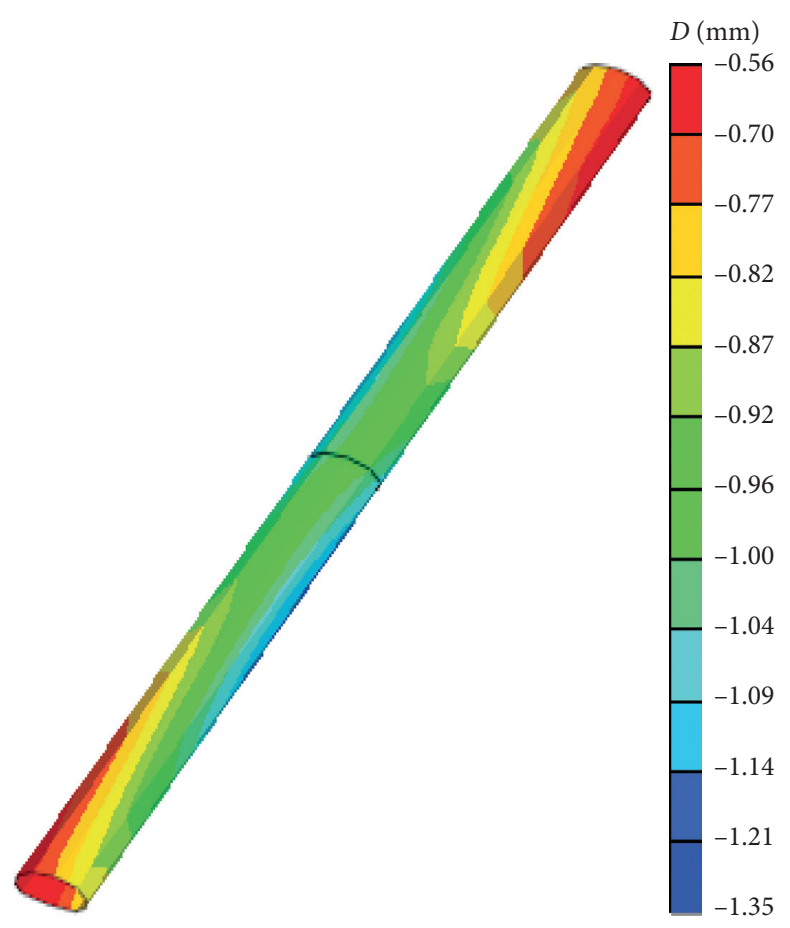

(a)

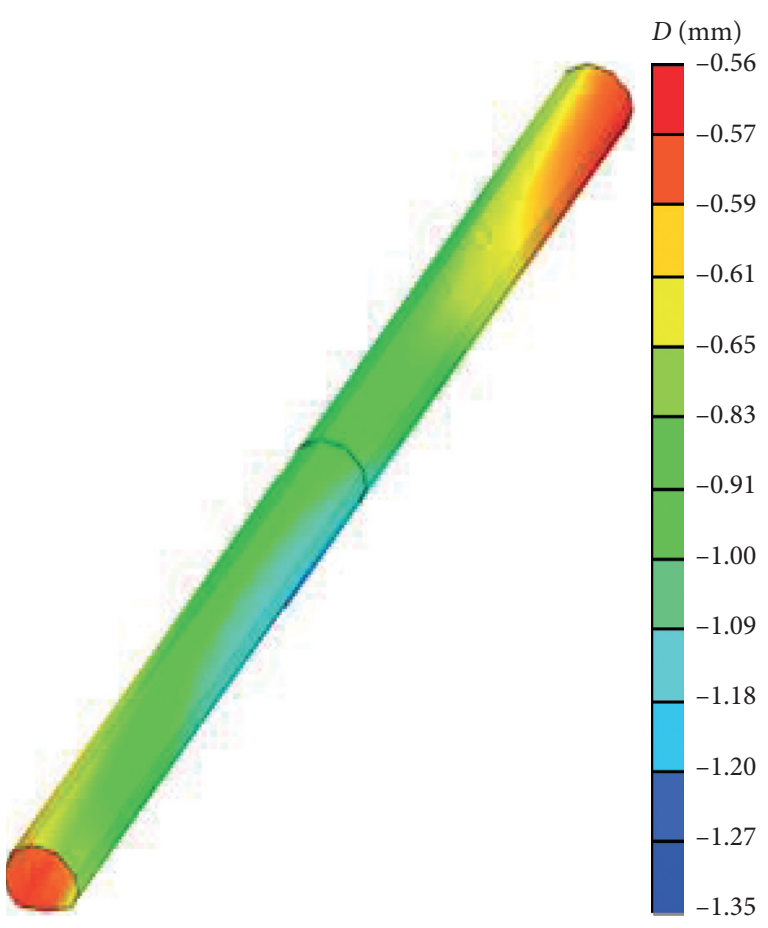

(b)

FIGURE 5: Cloud diagram of vertical settlement of the existing tunnel lining. (a) Excavation program I. (b) Excavation program II.

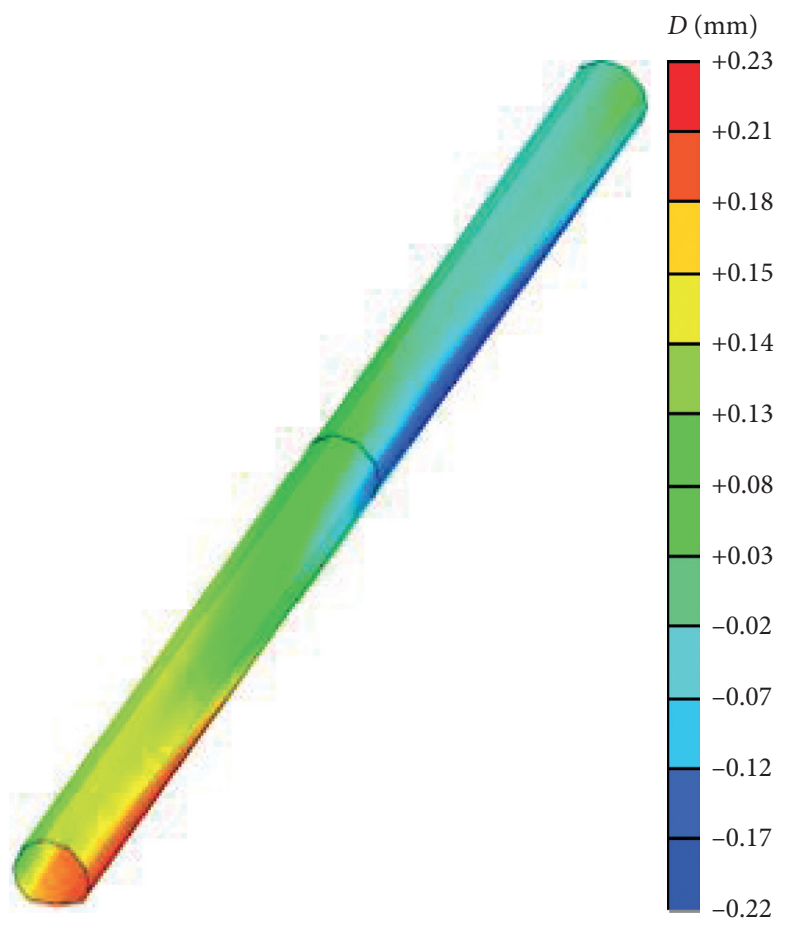

(a)

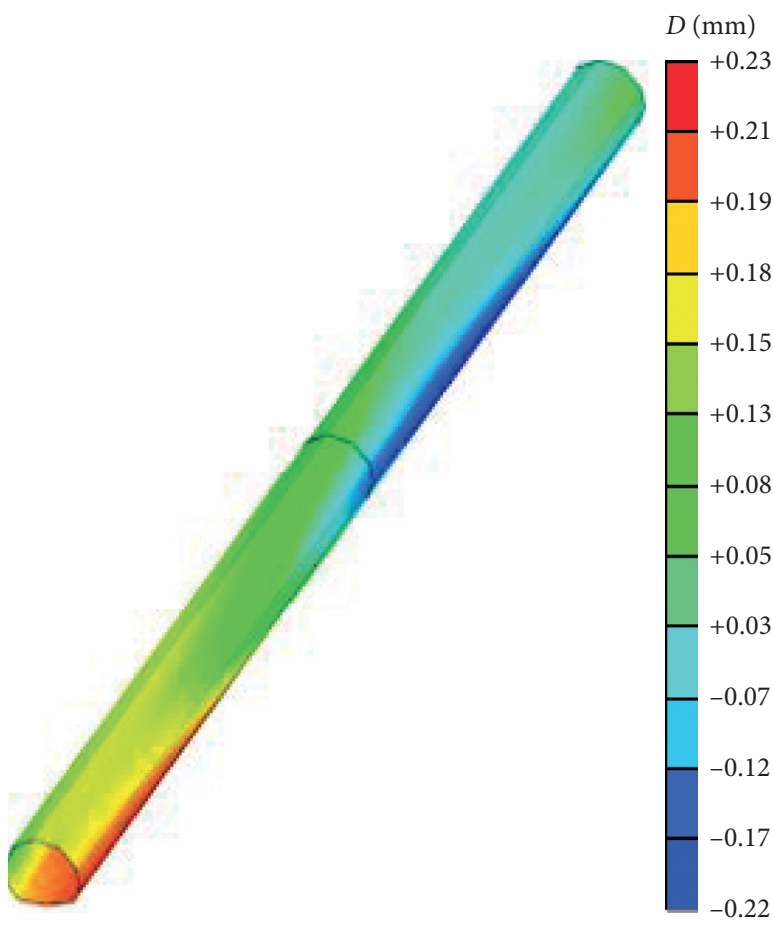

(b)

FIGURE 6: Cloud diagram of horizontal displacement of the existing tunnel lining. (a) Excavation program I. (b) Excavation program II. 


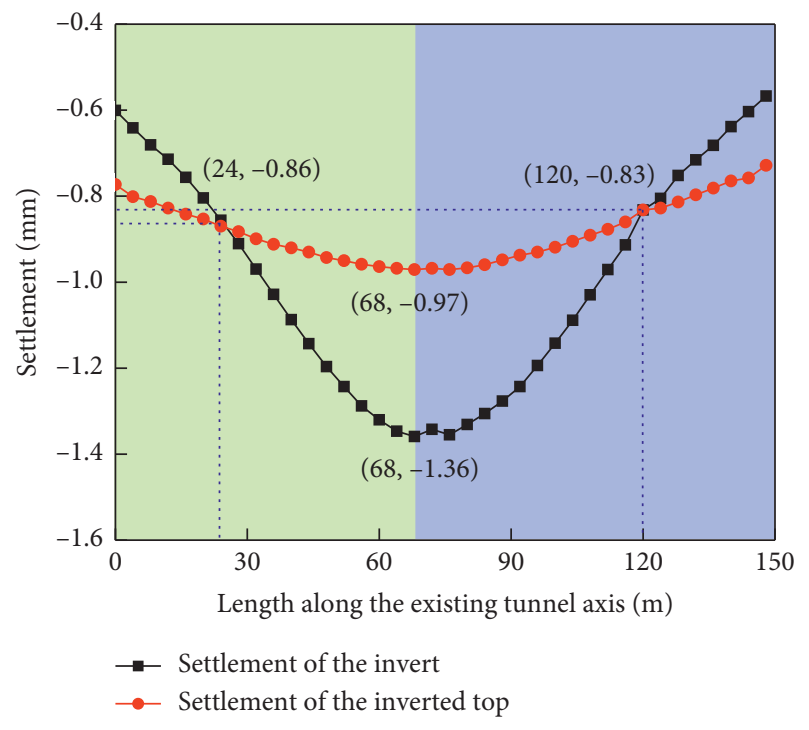

(a)

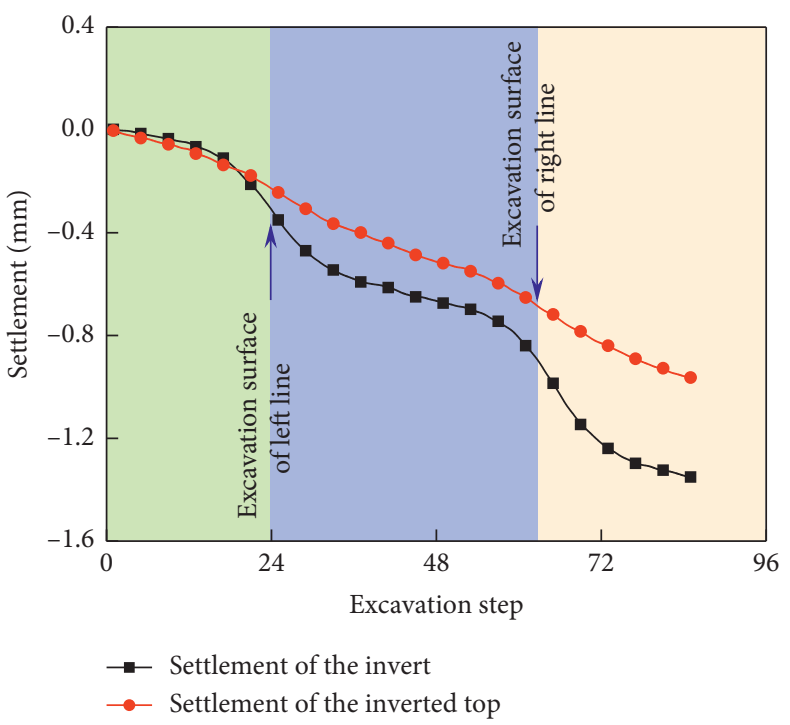

(b)

Figure 7: Settlement characteristics of invert and inverted top of the existing tunnel. (a) Relationship between settlement value and axial distance of invert and inverted top. (b) Relationship between settlement value and excavation step of invert and inverted top.

rate of the former being 1.35 times that of the latter. When the excavation step was in the range of 24 63, larger settlement occurred in both invert and inverted top and corresponding values were increased by $190 \%$ and $200 \%$ compared to previous stage, respectively, which was consistent with the characteristics of settlement curve. When the excavation step of the left line was greater than 63 , the settlement degree of inverted top was significantly higher than that of invert, showing an obvious stabilization stage in the later excavation. The settlement convergence values of invert and inverted top of the existing tunnel were $1.35 \mathrm{~mm}$ and $0.96 \mathrm{~mm}$, respectively.

Figure 8 shows the cloud diagrams of maximum principal stress of the existing tunnel lining after the construction of double-shield TBM. It was seen from Figure 8 that maximum principal stresses in invert area under the construction conditions of excavation programs I and II were larger, which were mainly manifested by tensile stresses of $0.99 \sim 2.43 \mathrm{~N} / \mathrm{mm}^{2}$ and $0.99 \sim 2.42 \mathrm{~N} / \mathrm{mm}^{2}$, and maximum principal stresses in invert waist area were mainly compressive stress of $2.20 \sim 3.09 \mathrm{~N} / \mathrm{mm}^{2}$ and $2.20 \sim 3.08 \mathrm{~N} / \mathrm{mm}^{2}$, respectively. It was seen that the influences of excavation programs I and II on the maximum principal stress of the existing tunnel lining were basically the same.

\subsection{Deformation Characteristics of Newly Built Tunnel.} Figure 9 shows the cloud diagram of the rock mass settlement of the newly built tunnel due to TBM construction where negative values represent rock settlement mass and positive values represent rock mass uplift. It was seen from Figure 9 that the vertical settlement displacement of rock mass due to TBM excavation under the two tunneling programs was relatively small. Maximum vertical settlement occurred in the rock mass area above inverted top and maximum uplift was observed at invert bottom. When excavation program I was completed, the maximum values of rock mass settlement and uplift due to TBM excavation unloading were 3.78 and $2.56 \mathrm{~mm}$, respectively, while excavation program II generated the maximum rock mass settlement and uplift of 3.80 and $2.57 \mathrm{~mm}$, which indicated an increase of only $0.53 \%$ and $0.34 \%$, respectively. It could be concluded that excavation programs I and II had little effect on the rock mass settlement of the newly built tunnel and sedimentation characteristics were similar.

Based on the above numerical analyses, it could be concluded that, according to the Code for Monitoring Measurement of Urban Rail Transit Engineering (GB50911-2013) [4, 7], the maximum allowable value of surface settlement reached $20 \mathrm{~mm}$ and surface settlement rate reached $4 \mathrm{~mm} /$ day as a control node for surrounding rock stability which could effectively guarantee the safe construction of surrounding rock and effectively control construction efficiency. It was also found that the corresponding maximum settlement values of rock mass obtained for excavation programs I and II were $12.60 \%$ and $12.67 \%$ of the maximum allowable settlement value, respectively, indicating that the rock masses of the newly built left and right lines were under relatively stable and safe construction conditions.

Figure 10 shows the cloud diagram of the horizontal deformation of the newly built tunnel due to TBM construction according to excavation programs I and II. It could be seen that horizontal deformation due TBM excavation unloading was relatively small and corresponding values for left and right lines were symmetrical about the longitudinal centerlines of the two tunnels. The maximum horizontal deformation of the tunnel model was distributed in the left area of the left line (upper left was more deformed than lower left) and right area of the right line (upper right was more deformed than lower right). Maximum horizontal deformations obtained by excavation program I were $0.19 \sim 0.55 \mathrm{~mm}$ and $0.25 \sim 0.56 \mathrm{~mm}$; those caused by 


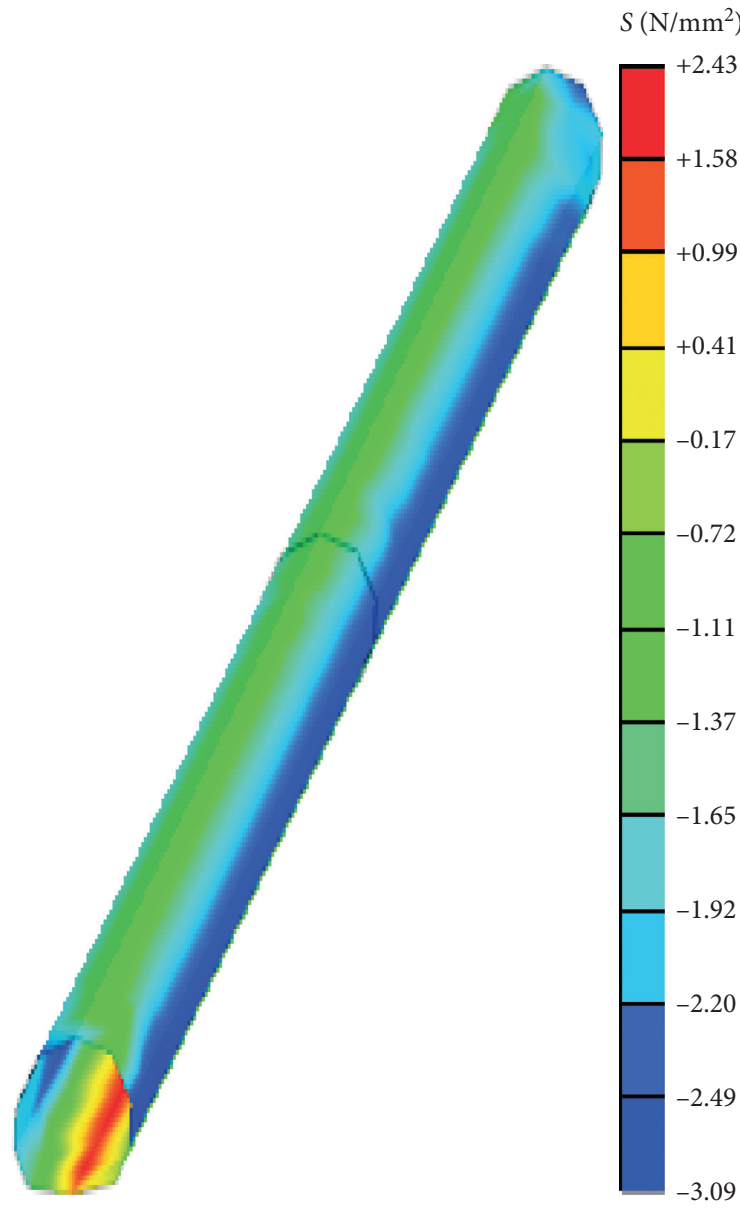

(a)

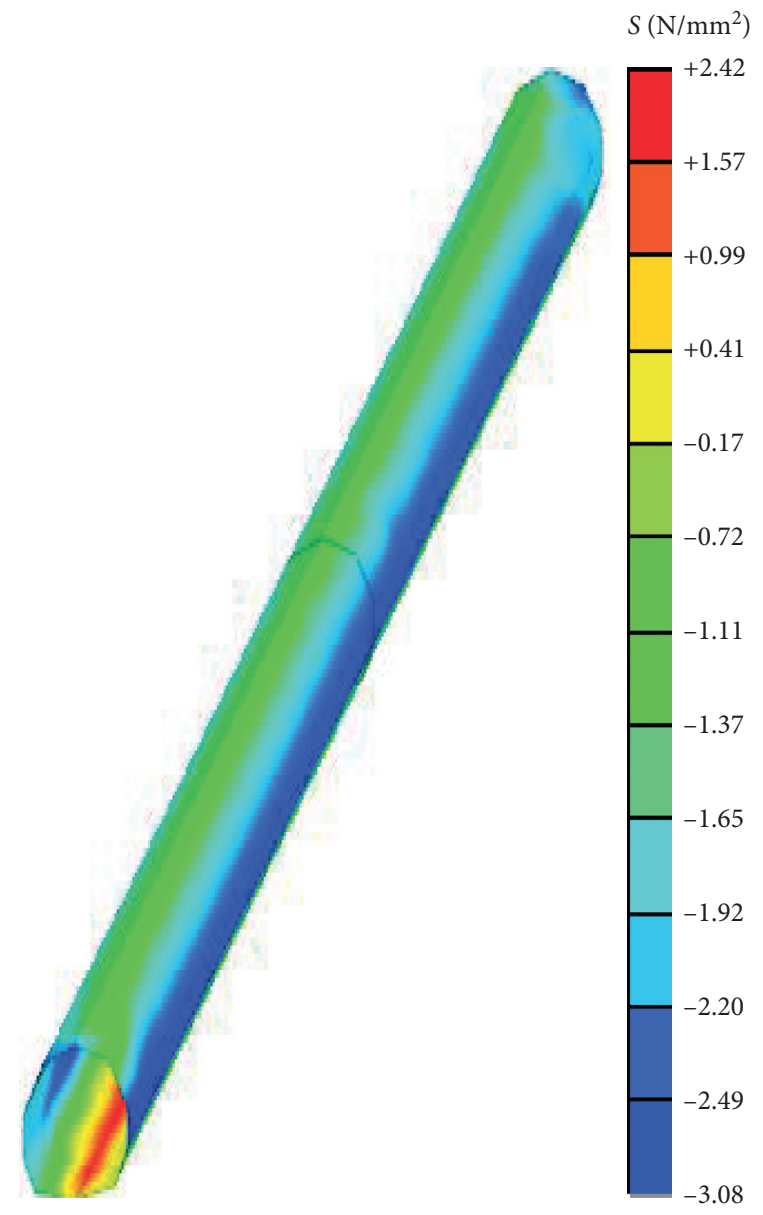

(b)

FIGURE 8: Cloud diagram of maximum principal stress of the existing tunnel lining. (a) Excavation program I. (b) Excavation program II.

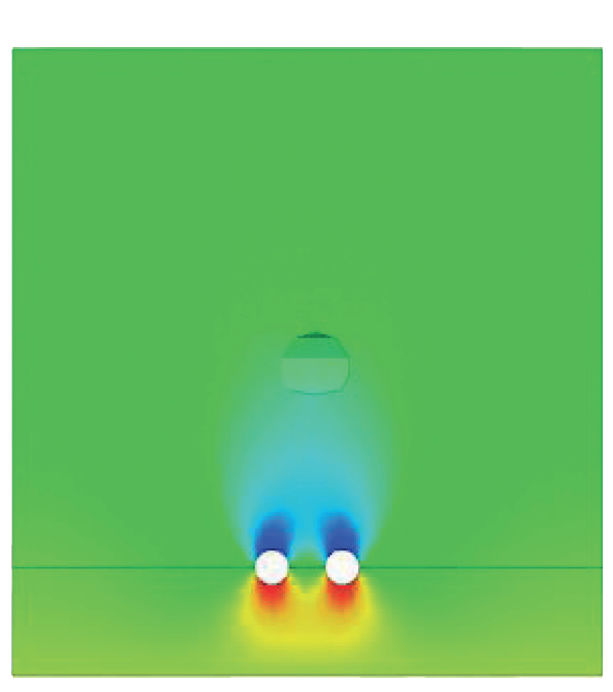

(a)
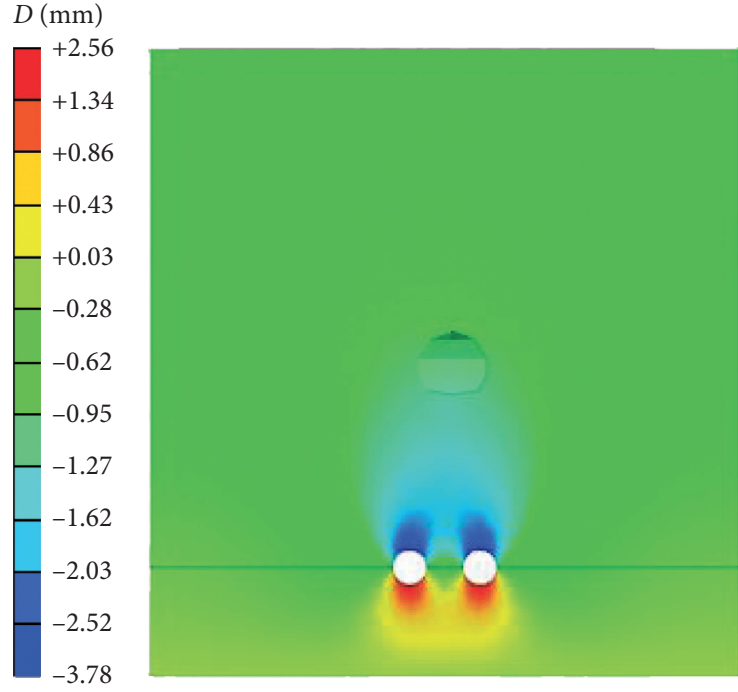

(b)

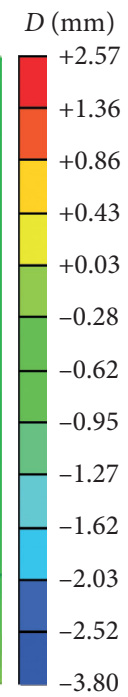

FIgURE 9: Cloud diagram of rock mass settlement of the newly built tunnel. (a) Excavation program I. (b) Excavation program II. 


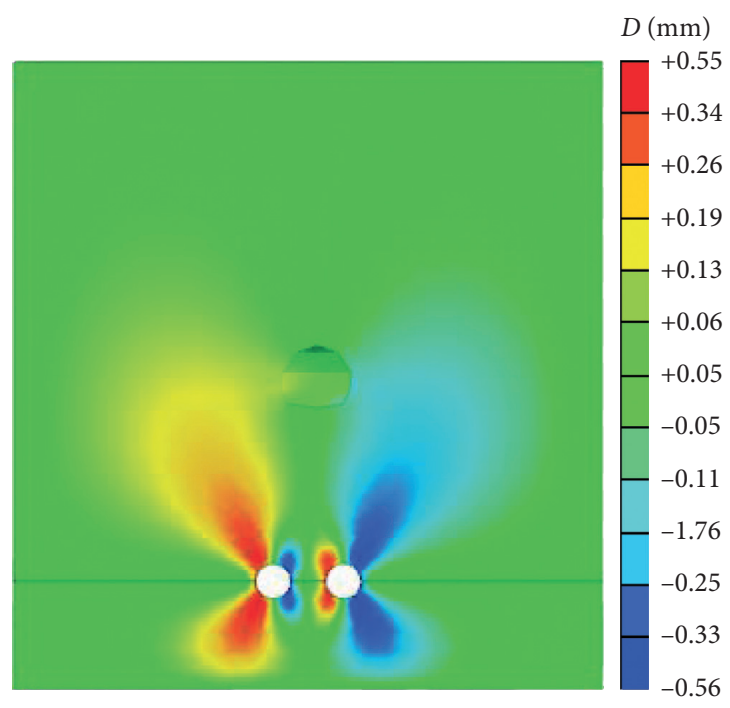

(a)

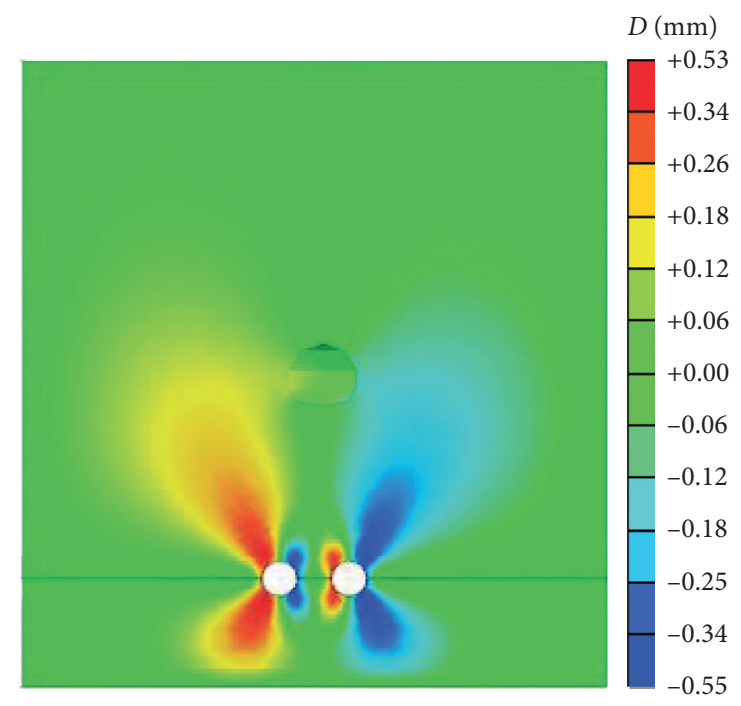

(b)

FIGURE 10: Cloud diagram of horizontal deformation of the newly built tunnel. (a) Excavation program I. (b) Excavation program II.

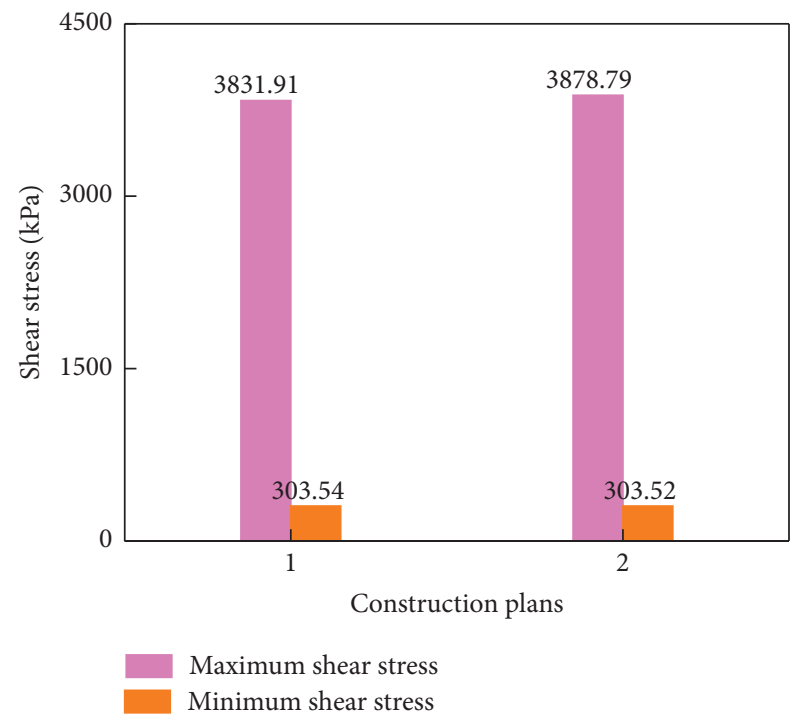

FIgURE 11: Maximum shear stress of the newly built tunnel.

excavation program II were $0.18 \sim 0.53 \mathrm{~mm}$ and $0.25 \sim 0.55 \mathrm{~mm}$, respectively. It was concluded that the two excavation programs had the same influence on the horizontal deformation of the newly built tunnel and maximum horizontal deformation due to excavation unloading was less than the control value $(5 \mathrm{~mm})$ of stable deformation [23].

Figure 11 shows the maximum shear stresses of the rock mass of the newly built tunnel under excavation following programs I and II. It was seen from Figure 11 that the distribution area of larger rock mass shear stress mainly appeared on the left and right sides of the tunnel. The maximum shear stress values of invert and inverted top areas were generally lower than the corresponding values on both sides and the increase of distance from the tunnel lining structure decreased the value of maximum shear stress.
Maximum shear stress values after construction were $3831.91 \mathrm{kPa}$ and $3878.79 \mathrm{kPa}$ while minimum shear stress values were $303.54 \mathrm{kPa}$ and $303.52 \mathrm{kPa}$, respectively.

Figure 12 shows the cloud diagram of the plastic deformation region of the newly built tunnel under excavation programs I and II. It was seen that the plastic deformation of the newly built tunnel presented an overall "butterfly" shape distribution. Newly built areas with larger plastic deformations mainly occurred around tunnel rock mass and disturbance range due to the TBM excavation unloading of single tunnel was $3.35 \mathrm{~m}$ (about 0.55 times tunnel diameter), while the influence range of excavation disturbance in double-line tunnels was $7.91 \mathrm{~m}$ (about 1.30 times tunnel diameter). Combined with the analysis of the unloading effect of TBM excavation, it was suggested that the excavation and supporting of the newly built tunnel caused inconsistency in the variations of vertical and horizontal stress in surrounding rock $[22,23]$ resulting in the redistribution of stress between left and right lines. Moreover, in the middle rock pillar area of the tunnel, the stability of the left line was higher than that of the right line. It was concluded from the above analyses that the plastic deformations of surrounding rock mass due to different excavation procedures in the newly built tunnel were basically consistent.

\subsection{Deformation Characteristics of Tunnel Segment}

3.3.1. Deformation Characteristics of Newly Built Tunnel Segment. Figure 13 shows the cloud diagram of the vertical settlement of the newly built tunnel segment following excavation programs I and II, where negative and positive values indicated the settlement and uplift of the segment, respectively. It was seen from Figure 13 that the top of the newly built tunnel segments had a vertical settlement with settlement ranges of $2.09 \sim 3.24 \mathrm{~mm}$ and $2.06 \sim 3.22 \mathrm{~mm}$, respectively. It was found that vertical settlement mainly 


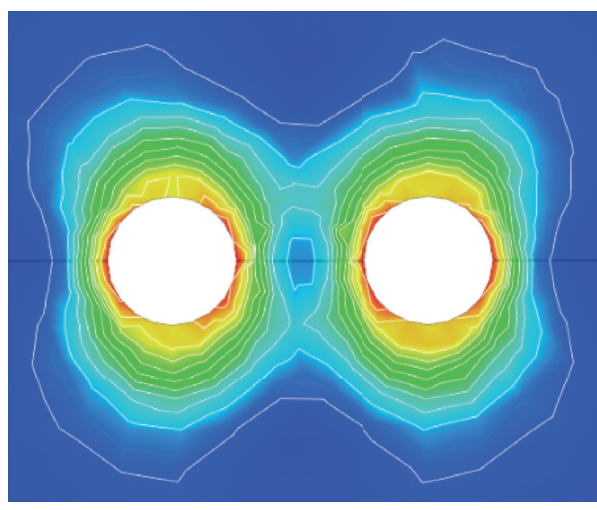

(a)

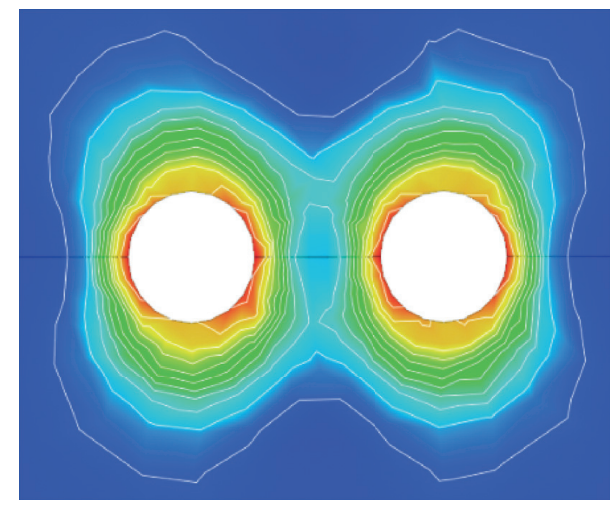

(b)

Figure 12: Cloud diagram of plastic deformation of the newly built tunnel. (a) Excavation program I. (b) Excavation program II.

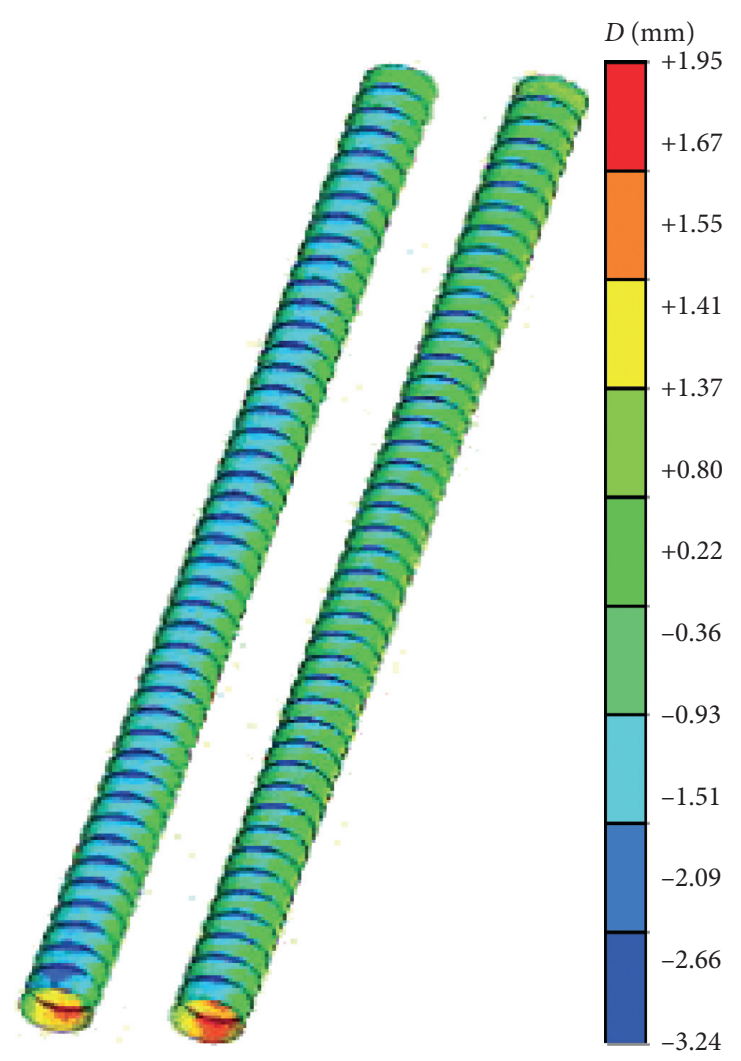

(a)

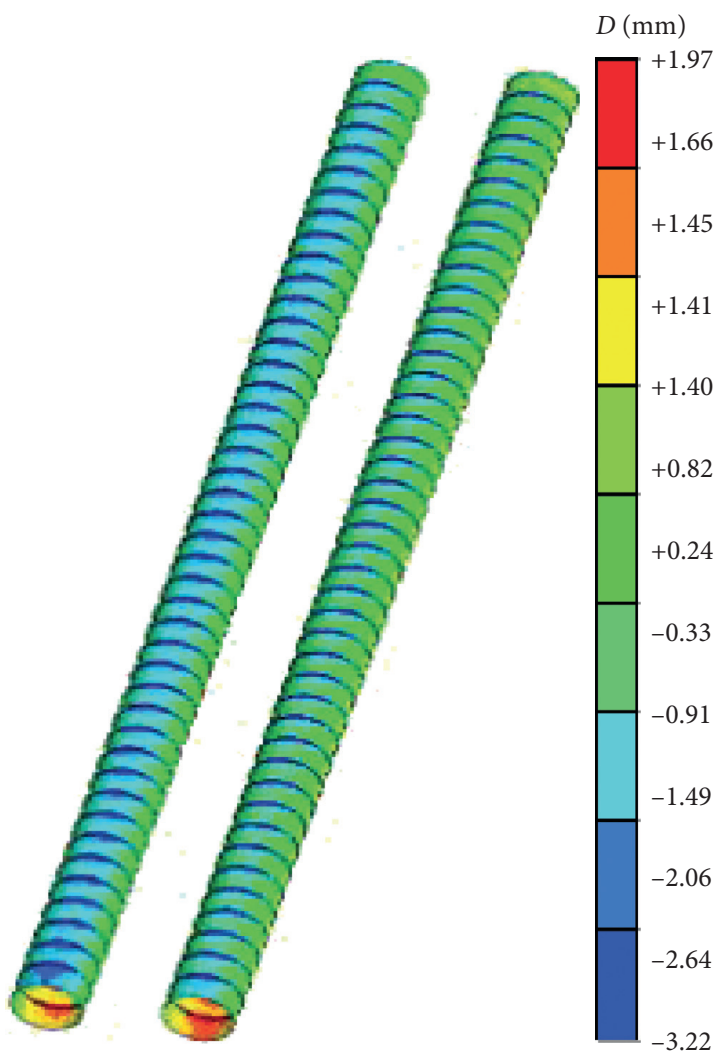

(b)

Figure 13: Cloud diagram of the vertical settlement of the newly built tunnel segment. (a) Excavation program I. (b) Excavation program II.

occurred at segment top with settlement ranges of $2.09 \sim 3.24 \mathrm{~mm}$ and $2.06 \sim 3.22 \mathrm{~mm}$, respectively. Uplift deformation mainly occurred at segment bottom with uplift ranges of $1.55 \sim 1.95 \mathrm{~mm}$ and $1.45 \sim 1.97 \mathrm{~mm}$, respectively. It was concluded that the settlement degree of tunnel segment for excavation program I was greater than that of program II and the two excavation programs had a similar effect on the uplift deformation of segment bottom. Average uplift deformations at segment bottom tunnel were $65.67 \%$ and $64.77 \%$ of the average settlement value at segment top, respectively, indicating that the segment deformation of the newly built tunnel was dominated by top settlement due to the effect of excavation unloading.

Figure 14 shows the cloud diagram of the horizontal deformation of the newly built tunnel segment following excavation programs I and II where negative and positive values indicated deformation points outside and inside the tunnel, respectively. It was seen from Figure 14 that the maximum horizontal displacements of left and right segments under the two excavation programs were basically the same, where the corresponding values were 0.40 and $0.39 \mathrm{~mm}$, respectively. The distribution patterns of the 


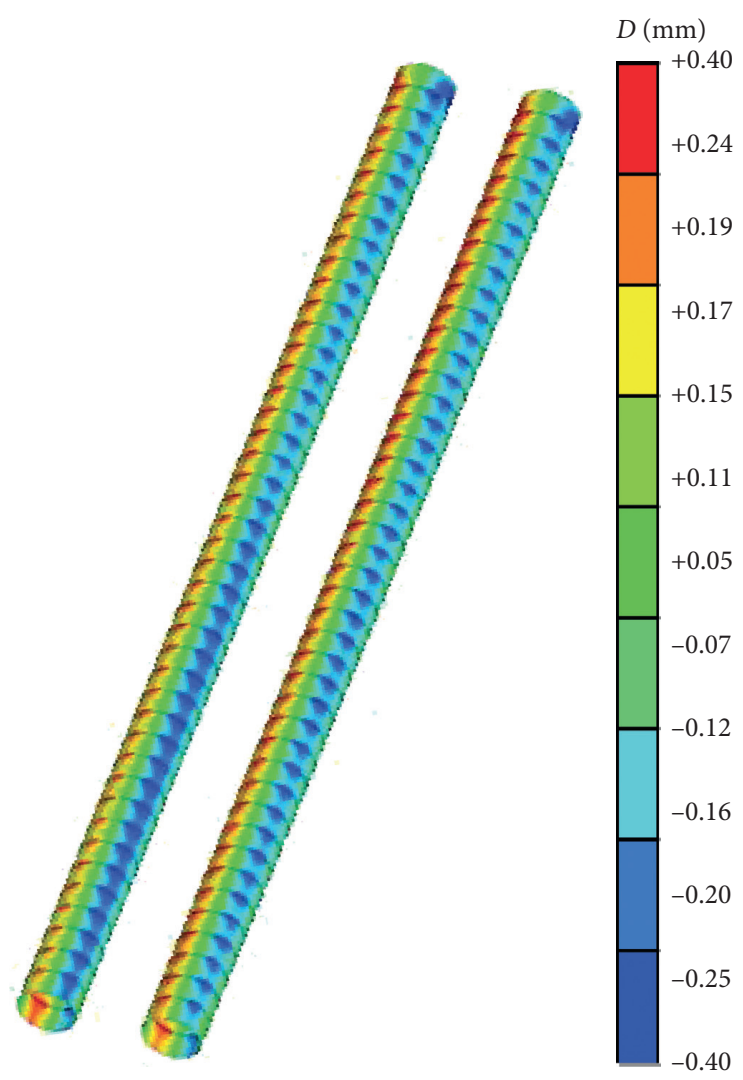

(a)

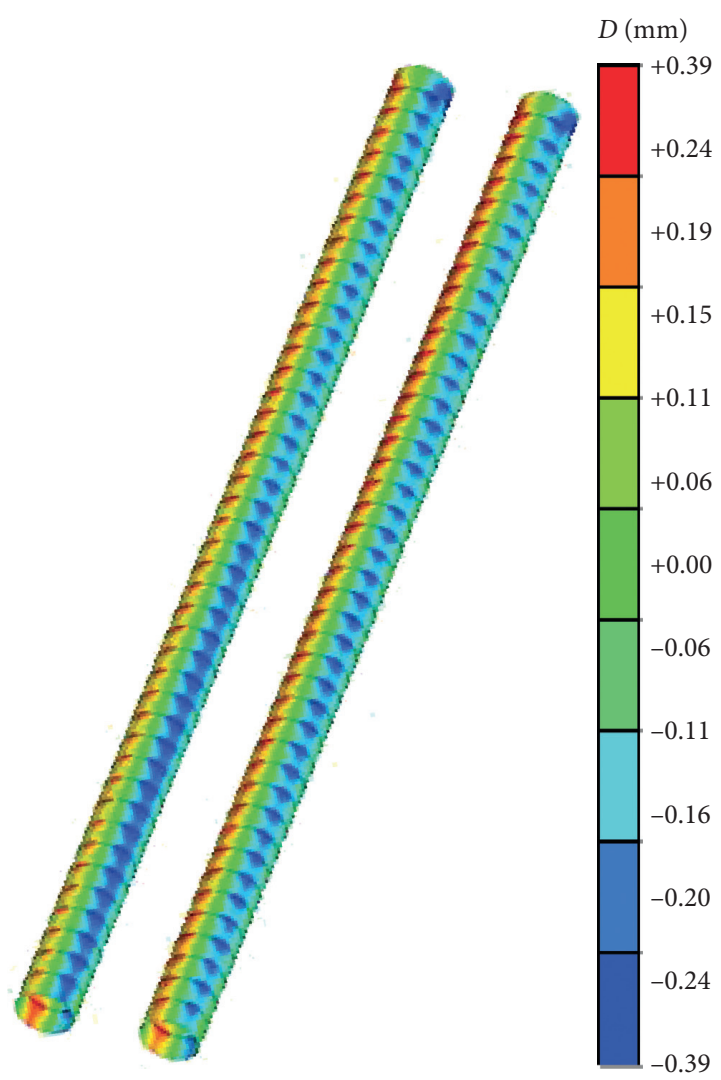

(b)

FIGURE 14: Cloud diagram of horizontal deformation of the newly built tunnel segment. (a) Excavation program I. (b) Excavation program II.

horizontal deformations of the tunnel segments of the left and right lines were consistent. The upper left, lower left, upper right, and lower right areas of the two tunnels show the deformation pointing into the tunnel, while the middle area all shows the deformation pointing out of the tunnel.

\subsubsection{Deformation Characteristics of Existing Tunnel} Segment. Taking the settlement characteristics of the existing tunnel segment following excavation programs I and II as research objects, Figure 15 shows settlement development trends at the top and bottom segments of the existing tunnel with progress of excavation steps where negative and positive values represent the settlement and uplift of the segment.

It was seen from Figure 15(a) that the settlement curve at the segment top of the left line tunnel presented phased settlement at the left line (excavation step 24) and right line (excavation step 63) excavation faces. With the increase of the excavation step, the settlement curve of the segment top showed four development stages of no settlement, rapid settlement, stable settlement, and convergence settlement. Before the excavation step reached the excavation face of the left line ( $x$ values of lower than 24), there was almost no vertical settlement at segment top where the settlement range was only $0 \sim 0.93 \mathrm{~mm}$. When the excavation step gradually reached the excavation face of the left line $(x=24)$, significant vertical settlement occurred at segment top with a settlement range of $1.10 \sim 2.20 \mathrm{~mm}$ and average settlement $(1.65 \mathrm{~mm})$ was 3.51 times that of the former $(0.47 \mathrm{~mm})$. When the excavation step was between excavation faces of the left and right lines ( $x$ values in the range of 24 to 63 ), the segment top settlement curve showed a stable trend with a settlement value of $2.50 \sim 2.90 \mathrm{~mm}$. In this stage, the average settlement value $(2.70 \mathrm{~mm})$ was 1.64 times that of the former $(1.65 \mathrm{~mm})$, indicating that the stability monitoring of the construction site had to be strengthened. When the excavation step was greater than the excavation face of the left line ( $x$ value of greater than 63), the settlement curve of segment top tended to be stabilized and the converged settlement value of $3.09 \mathrm{~mm}$ was obtained which was about 1.15 times the average settlement value of the former $(2.70 \mathrm{~mm})$.

It was seen from Figure 15(b) that, under the unloading effect of the excavation of the newly built tunnel, the settlement curve at the segment bottom of the existing tunnel indicated an opposite development trend with the progress of excavation steps. The development curve also exhibited significant uplift deformation near the excavation faces of left $(x=24)$ and right $(x=63)$ lines indicating the four development stages of no uplift, rapid uplift, slow uplift, and finally convergence uplift. When the excavation step was 


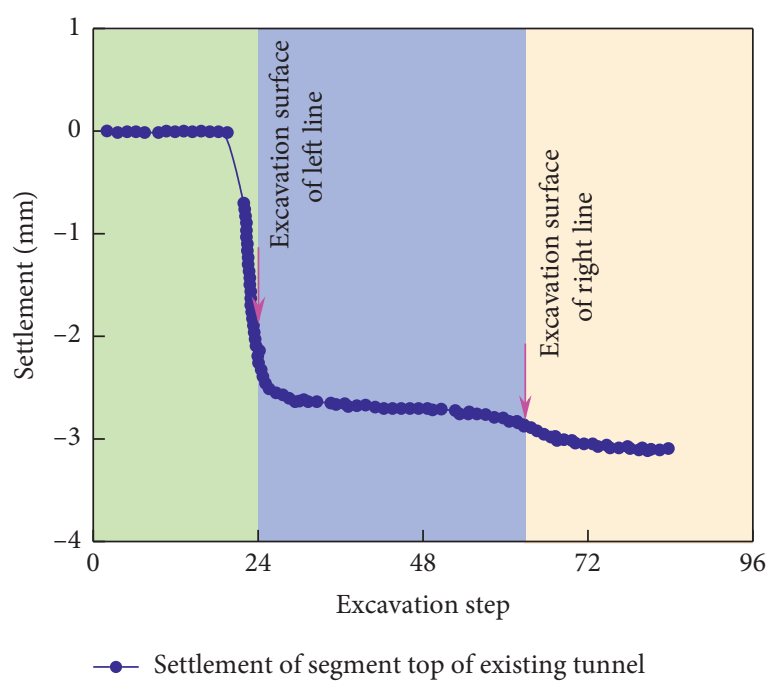

(a)

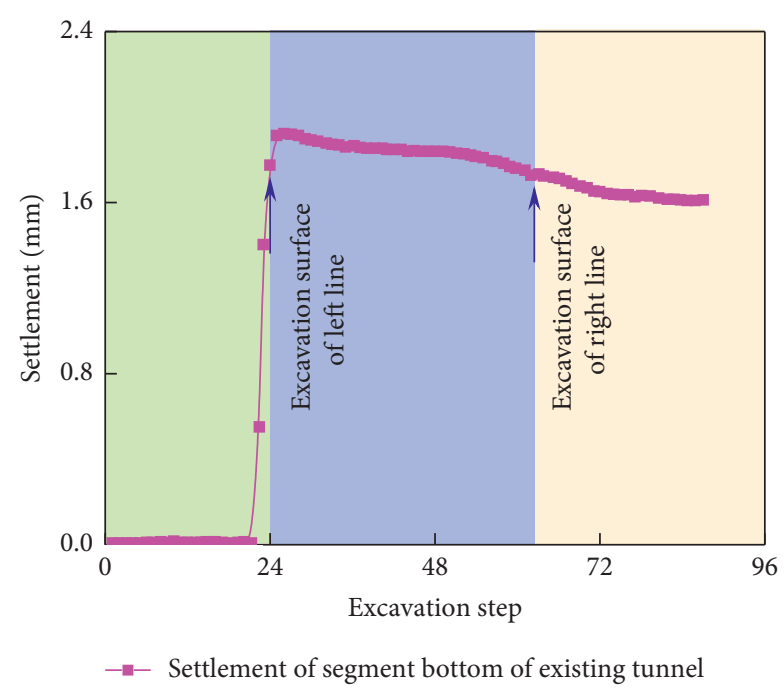

(b)

FIGURE 15: Development trend of settlement at segment top and segment bottom of the existing tunnel with increasing excavation step. (a) Settlement of segment top. (b) Settlement of segment bottom.

lower than 24, almost no significant uplift deformation was observed at segment bottom with uplift deformation of 0 to $0.55 \mathrm{~mm}$. When the excavation step was in the range of $24 \sim 63$, the uplift deformation of the bottom segment was sharply increased from 0.55 to $1.92 \mathrm{~mm}$ corresponding to $249.10 \%$. It is noteworthy that the settlement curve of this section showed a slowly decreasing trend due to small excavation disturbance after excavation steps of greater than 24 , with uplift deformations of $1.72 \sim 1.92 \mathrm{~mm}$. When the excavation step exceeded 63, uplift deformation at segment bottom tended to stabilize gradually with uplift values of $1.61 \sim 1.72 \mathrm{~mm}$.

The above numerical simulation results showed that the maximum settlement of the newly built tunnel structure during TBM underpass excavation was $3.24 \mathrm{~mm}$ and corresponding values for the existing tunnel structure under two excavation programs were 2.90 and $1.92 \mathrm{~mm}$, respectively, which met the control range of allowable values $(5 \mathrm{~mm})$. Hence, the application of the TBM excavation method to carry out underpass construction was considered to be reasonable and safe. According to simulation results, the effects of the two excavation programs on the deformation of the existing tunnels were the same and rock mass settlement and tunnel structure deformation were within the control standard range $[22,23]$. Moreover, considering that the left line of the newly built tunnel was near Yangtai Mountain and the raft foundation was arranged at the right line, the first excavation of the left line was beneficial to the hoisting and residue transportation of the right line.

\section{Monitoring and Analysis of Existing Tunnel}

4.1. Monitoring Site Layout and Contents. Based on the above optimization program, the double-shield TBM excavation method was applied for the prioritization of the construction of the left line tunnel of Shenzhen Metro Line 6. Tentative excavation test was conducted before the construction of the underpass section for the determination of TBM tunneling parameters. The tunneling pressure range of double-shield TBM and tunneling speed range as well as the torque control range, speed control range, and penetration range of cutter head were found to be $8000 \sim 10000 \mathrm{kN}, 10 \sim 18 \mathrm{~mm} / \mathrm{min}$, $6000 \sim 9000 \mathrm{kN} \cdot \mathrm{m}, 3 \sim 4.5 \mathrm{rpm}$, and $2 \sim 4.5 \mathrm{~mm} / \mathrm{r}$, respectively. During the TBM tunneling process, the data of surrounding rock mass and structural deformation obtained for the new tunnel were also monitored to dynamically adjust the tunneling parameters of TBM to ensure the smooth crossing of TBM. During the TBM tunneling process, data of surrounding rock mass and structural deformation of the newly built tunnel are also monitored to dynamically adjust the TBM tunneling parameters to ensure the smooth excavation.

According to The Code for Monitoring Measurement of Urban Rail Transit Engineering (GB50911-2013) and actual site conditions, the monitoring level of the existing tunnel was secondary monitoring. Therefore, monitoring sections DK25 + 870 and DK25 + 880 were set to monitor the settlement and deformation characteristics of the surrounding rock. Monitoring sections were $10 \mathrm{~m}$ away from each other, 3 monitoring points were arranged in each monitoring section with a monitoring frequency of once a day (monitoring frequency was increased when tunnel deformation was too large), and continuous monitoring duration was 81 days. The automated monitoring method [35] was to evaluate the influence of excavation unloading on the stability of the existing tunnel without interfering with the normal operation of high-speed trains. Measuring points were arranged according to Figure 16; that is, measuring point 1 monitored the invert settlement and measuring points 2 and 3 monitored the horizontal deformation of the existing tunnel.

4.2. Monitoring Results and Analysis. The time-history curves of invert settlement and horizontal deformation in 


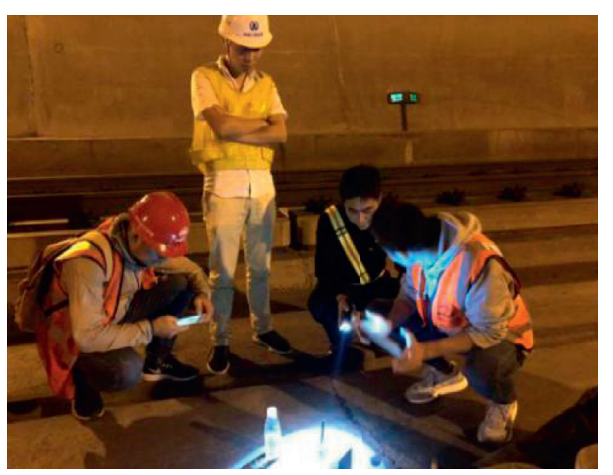

(a)

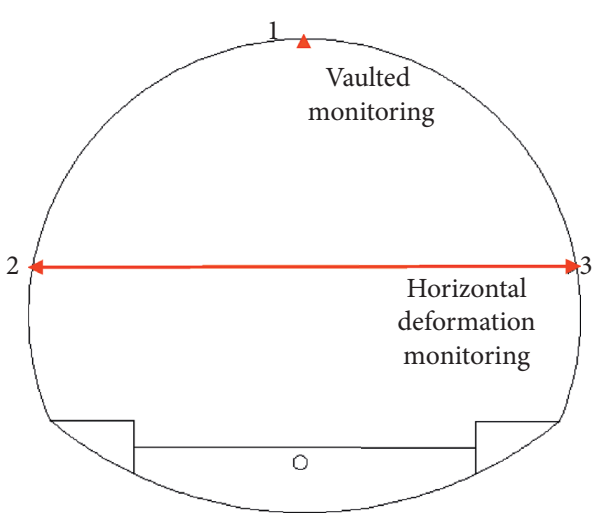

(b)

FIGURE 16: Monitoring of settlement and horizontal deformation of the existing tunnel. (a) Monitoring site. (b) Layout of measuring points.

the characteristics sections (DK25 + 870 and DK25 + 880) of the existing tunnel due to excavation unloading effect were obtained based on the monitoring plan presented in Figure 16 and monitoring data obtained from the construction site. Monitoring data were analyzed in terms of the invert settlement and horizontal deformation characteristics of the existing tunnel.

4.2.1. Settlement Characteristics of Existing Tunnel Invert. Figure 17 shows the time-history curves of the tunnel invert of the characteristic sections DK25 +870 and DK25 +880 of the existing tunnel. It was seen from Figure 17 that the unloading effect of TBM excavation significantly affected the invert settlements of the existing tunnel at the abovementioned two characteristic sections, resulting in the formation of three development stages in a time-history curve, that is, a slow settlement followed by a sharp settlement and finally a stable settlement.

It could be concluded from Figure 17(a) that when the excavation time of the newly built tunnel was lower than 19 days, lower unloading of surrounding rock caused the tunnel vault of characteristic section DK25+870 to slowly settle with settlement values of 0.30 to $0.71 \mathrm{~mm}$ and average settlement of $0.51 \mathrm{~mm}$. When the excavation time of the surrounding rocks of the newly built tunnel was greater in the range of 19 29 days, the existing tunnel showed great settlement deformations and rapid settlements were observed in invert. The average settlement was quickly increased by $1.38 \mathrm{~mm}$ (from 0.51 to $1.89 \mathrm{~mm}$ ) corresponding to an increase of 2.71 times. The supporting role of upper surrounding rock was enhanced with the timely implementation of supporting structure in the newly built tunnel and the deformation degree of upper surrounding rock due to construction disturbance was significantly decreased. At this time, the time-history curve of invert settlement gradually entered a stable convergence stage at the excavation times of greater than 29 days. In the stable convergence stage, the settlement curve was changed in an oscillatory manner with almost linear development trend and settlement values of 1.30 1.52 mm. Regression analysis showed that the invert settlement of characteristic section
DK25 + 870 varied with excavation time as a first-order exponential function.

It was concluded from Figure 17(b) that, due to the unloading effect during the excavation of the newly built tunnel, the tunnel invert of characteristic section DK25 + 880 presented a similar settlement trend and the demarcation points of the two stages were 19th and 29th days. The amount of settlement in the slow settlement stage was $0.29 \sim 0.70 \mathrm{~mm}$ with a settlement rate of $0.02 \mathrm{~mm} /$ day. In the sharp settlement stage, the average settlement range was $0.54 \sim 1.44 \mathrm{~mm}$ with a settlement rate of $0.09 \mathrm{~mm} /$ days, which was 4.50 times higher than that in the previous stage. At excavation times of greater than 29 days, tunnel invert gradually entered the stable settlement stage and time-history curve was developed in a stable manner with settlement values of 1.30 1.54 mm. Regression analysis showed that the invert settlement of characteristic section DK25 + 880 was varied in a first-order exponential function with the increase of excavation time.

It was concluded from the above discussions that the maximum settlement values of the existing tunnel vault at the two characteristic sections were $1.52 \mathrm{~mm}$ and $1.54 \mathrm{~mm}$, respectively. Due to the effect of the excavation of the new tunnel, the two settlement values were significantly greater than those obtained by previous numerical calculations to be $1.36 \mathrm{~mm}$ and $0.97 \mathrm{~mm}$. This was because tunnel rock mass was assumed to be a uniform, homogeneous, and continuous medium in the numerical model, without taking into account the joint defects of natural rock mass and other influential factors. In addition, the developed numerical model ignored the loading effects of train operation on the invert settlement of the existing tunnels. The analysis of the invert settlement of the existing tunnel showed that the theoretically obtained settlement value $(1.36 \mathrm{~mm})$ from the developed numerical model corresponded to $89.47 \%$ and $88.31 \%$ of the actual settlement values of $1.52 \sim 1.54 \mathrm{~mm}$. It was concluded that the settlement law of the actual tunnel vault could be effectively predicted based on model analysis results.

4.2.2. Horizontal Deformation Characteristics of Existing Tunnel. Figure 18 shows the time-history curves of the 


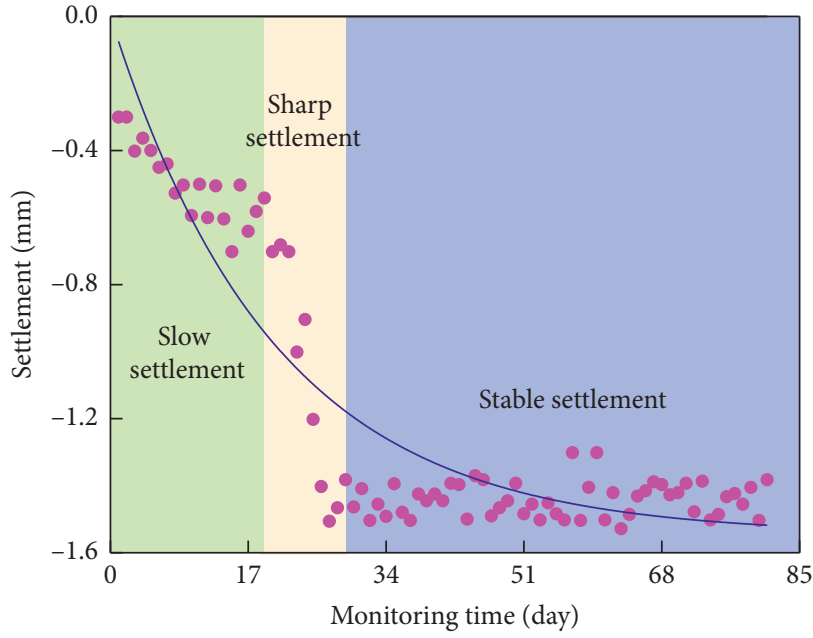

- Settlement of the inverted top of existing tunnel - First order exponential function

(a)

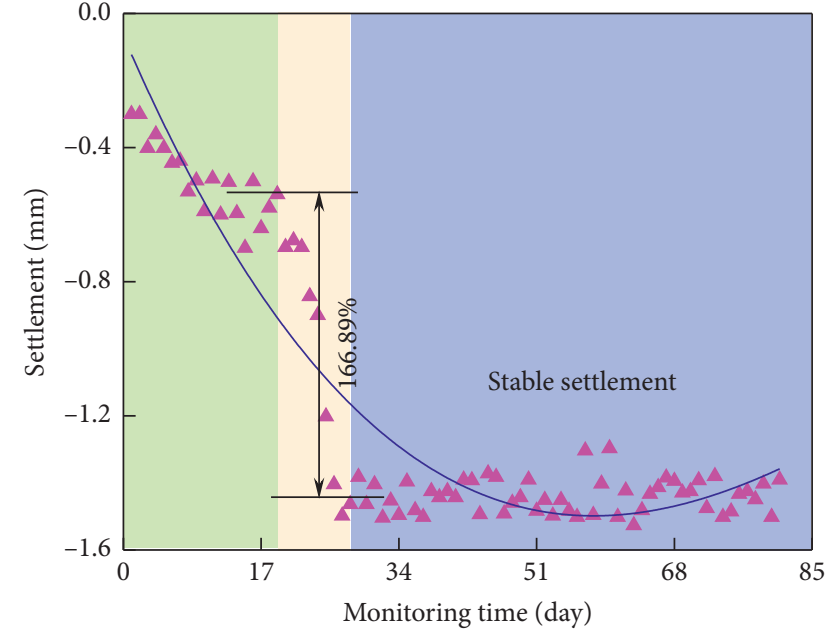

- Settlement of the inverted top of existing tunnel - Cubic function

(b)

FIgURE 17: Time-history curves of invert of characteristic DK25+870 and DK25+880 sections of the existing tunnel. (a) Section DK25 + 870. (b) Section DK25 + 880 .

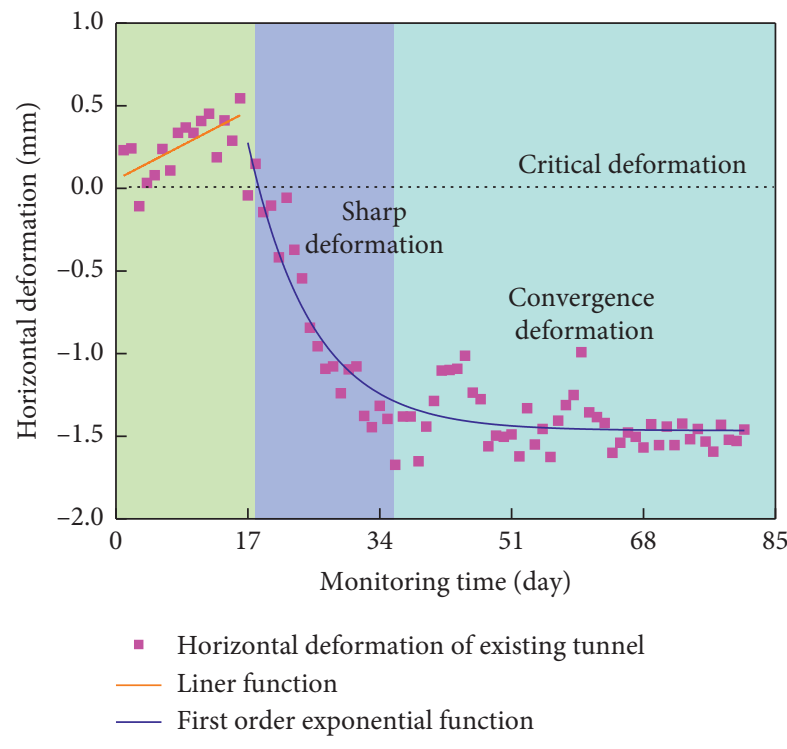

(a)

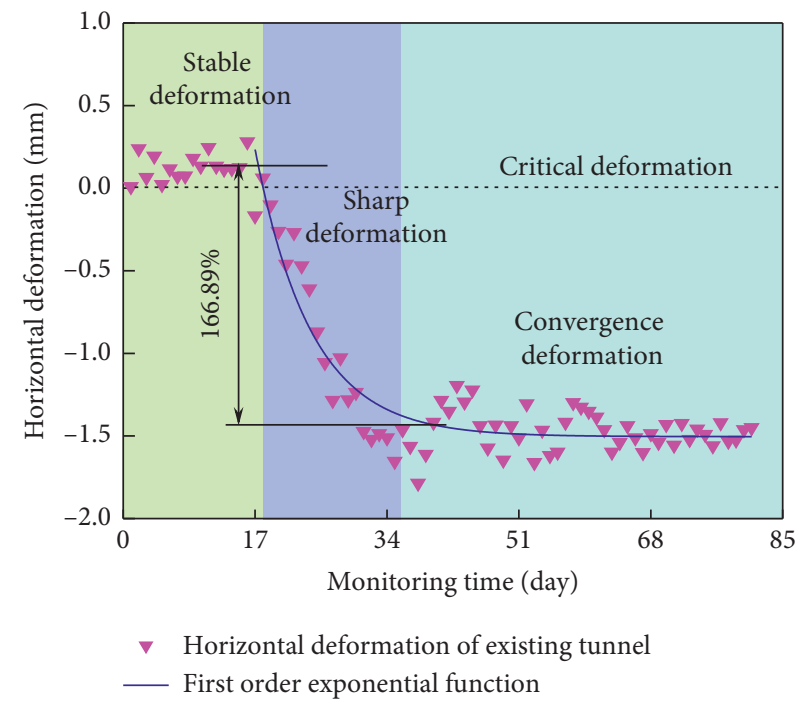

(b)

FIGURE 18: Time-history curves of horizontal deformation in characteristics sections of the existing tunnel. (a) DK25 + 870 section. (b) DK25 + 880 section.

horizontal deformation of characteristic sections DK25 + 870 and DK25 + 880 in the existing tunnel where positive and negative values above and below critical deformation indicated that deformation displacement pointed to the inside and outside of the tunnel, respectively. It was seen from Figure 18 that the excavation of the new tunnel had a significant influence on the horizontal deformations of characteristic sections DK25 +870 and DK25 + 880 and the variation trend of the time-history curve with the increase of monitoring time was basically the same. Comparative analyses showed that, on the 19th day of the excavation of the new tunnel, the horizontal deformation of two characteristic sections showed outward horizontal deformations with the values of $0.03 \sim 0.54 \mathrm{~mm}$ and $0 \sim 0.28 \mathrm{~mm}$, respectively. Before the 19th day of the excavation of the new tunnel, outward horizontal deformations were observed in the two characteristic sections with magnitudes of $0.03 \sim 0.54 \mathrm{~mm}$ and $0 \sim 0.28 \mathrm{~mm}$, respectively.

In addition, the development trends of time-history curves showed that the horizontal deformation of 
characteristic section DK25 +870 was increased almost linearly with the increase of monitoring time, while that of characteristic section DK25 + 880 was changed slowly with no significant increase. This indicated that the influence of excavation unloading on the horizontal deformation of characteristic section DK25+870 in 0 19th day was significantly greater than that of DK25+880. At monitoring times of longer than 19 days, the time-history curves of both characteristic sections DK25 +870 and DK25 +880 presented two stages, a sharp increase stage followed by a slow convergence. The demarcation points of monitoring time in the two stages were approximately the 36th day. The regression analysis of time-history curves on 19th 81 th day showed that the horizontal deformation of DK25+870 section was changed with the increase of monitoring time as a first-order exponential function, which was consistent with the development trend of settlement time-history curve shown in Figure 17.

It was seen from Figure 18(a) that, with the increase of monitoring time from 19th to 36th day, average horizontal deformation was increased from $1.26 \mathrm{~mm}$ outward to $-1.42 \mathrm{~mm}$ inward in characteristic section DK25 +870 which corresponded to an increase of $213.60 \%$, causing a sharp increase in time-history curve. At the monitoring times of longer than 36th day, the application of tunnel supporting structure reduced the deformation of overlying rock mass further weakening the horizontal deformation of the existing tunnel. Horizontal deformation gradually entered into a stable stage with an average convergence value of $1.42 \mathrm{~mm}$.

Figure 18(b) shows that the time-history curve of the horizontal deformation of characteristic section DK25 + 880 followed a similar development trend. At monitoring times in the range of 19th 36th day, the horizontal deformation of characteristic section DK25 + 880 was increased by $166.89 \%$, but this value was lower than the corresponding value for characteristic section DK25 +870 . At monitoring times of longer than the 36th day, horizontal deformation was significantly decreased and gradually entering the convergence deformation stage with an average convergence of $1.47 \mathrm{~mm}$. Compared with characteristic section DK25+870, the convergence value of the horizontal deformation of characteristic section DK25 + 880 was only increased by $11.90 \%$ with a deformation growth rate of $0.005 \mathrm{~mm} /$ day. From the above discussions, it could be concluded that the excavation of TBM had little effect on the horizontal deformations of the two characteristic sections and the existing tunnel was safe and stable.

\section{Conclusions}

(1) The excavation of the left and right lines of the newly built tunnel had similar effects on the deformation characteristics of the existing tunnel. The gap between the maximum settlement and maximum horizontal deformation of tunnel lining in the central area was obvious. The settlement curves of both invert and inverted top of the existing tunnel were first increased and then decreased before forming a
V-shaped settlement trough with the maximum settlement values of $1.36 \mathrm{~mm}$ and $0.97 \mathrm{~mm}$, respectively.

(2) The effects of excavation unloading on the settlement and deformation of the newly built tunnel were consistent. Maximum settlement values occurred in the upper surrounding rock of the inverted top of the tunnel, while maximum uplift values were obtained in the bottom surrounding rock of invert. The horizontal deformations of the left and right surrounding rocks were symmetric with respect to the middle line of the newly built tunnels.

(3) Excavation unloading had a significant effect on the segment settlements of the newly built and existing tunnels. The top settlement was the dominant settlement in left and right line segments while horizontal deformations mainly occurred in left and lower areas. The settlement curve of the segment top of the existing tunnel first showed no settlement stage followed by a rapid settlement, a stable settlement, and finally a convergence settlement stages, while bottom uplift presented an opposite development trend.

(4) Prioritization of left line excavation had obvious advantages in the operation of the existing tunnel and safe construction of the newly built tunnels compared with right line tunnel. On-site monitoring of the invert settlement of the existing tunnel revealed that the excavation unloading effect first caused a slow settlement followed by a rapid settlement and finally a stable settlement. The actual settlement values were 1.12 and 1.13 times the theoretical settlement, respectively.

\section{Data Availability}

The data used to support the findings of this study are available from the corresponding author upon request.

\section{Conflicts of Interest}

The authors declare that they have no conflicts of interest.

\section{Acknowledgments}

The authors would like to acknowledge the Innovation Capacity Support Plan of Shaanxi Province (2020TD-005), Project Foundation of Department of Housing and Urban Rural Development of Shaanxi Province (2019-K39), and Natural Science Basic Research Program of Shaanxi (2019JQ-762).

\section{References}

[1] M. S. Zhang, L. Gong, H. Y. Chen et al., "Research on the key technologies of construction of TBM interval tunnel across high-soeed railway tunnel," Journal of Railway Engineering Society, vol. 36, no. 7, pp. 76-80, 2019. 
[2] Z. P. Song, X. X. Tian, Q. Liu et al., "Numerical analysis and application of the construction method for small interval tunnel in the turn line of metro," Science Progress, vol. 103, no. 3, pp. 1-25, 2020.

[3] R. H. Mai, S. Li, W. B. Li et al., "Analysis of anti-overturn stability of curved beam bridge considering earthquake effects," Journal of Jiangxi University of Technology, vol. 41, no. 3, pp. 9-15, 2020.

[4] D. F. Xia, "Impact analysis of excavated tunnel undercrossing on south-to-north water transfer project," Journal of Jiangxi University of Technology, vol. 41, no. 3, pp. 24-30, 2020.

[5] T. Liu, Y. Xie, Z. H. Feng et al., "Better understanding the failure modes of tunnels excavated in the boulder-cobble mixed strata by distinct element method," Engineering Failure Analysis, vol. 116, pp. 1-23, 2020.

[6] K. Zhao, T. Y. Teng, P. Zeng et al., "Experimental study on acoustic emission characteristics of red sandstone under uniaxial compression with different water content," Journal of Jiangxi University of Technology, vol. 40, no. 5, pp. 1-7, 2019.

[7] H. Wu, Y. J. Zhong, W. Xu et al., "Experimental investigation of ground and air temperature fields of a cold-region road tunnel in NW China," Advances in Civil Engineering, vol. 2020, Article ID 4732490, 13 pages, 2020.

[8] C. F. Zhou, "Analysis and protective measures of city wall due to underneath crossing shield tunnel," Journal of Jiangxi University of Technology, vol. 40, no. 5, pp. 31-36, 2019.

[9] X. X. Tian, Z. P. Song, and J. B. Wang, "Study on the propagation law of tunnel blasting vibration in stratum and blasting vibration reduction technology," Soil Dynamics and Earthquake Engineering, vol. 126, Article ID 105813, 12 pages, 2019.

[10] G. Deng, H. W. Zhu, J. Zhou et al., "Modification of Peck formula based on construction of Guangzhou metro tunnel," Journal of Jiangxi University of Technology, vol. 40, no. 3, pp. 9-13, 2019.

[11] Q. Yin, Q. Liu, and S. He, “Analysis of stability and long term damage law of the flathead shaped excavated coal measure soil slope," Journal of Jiangxi University of Technology, vol. 40, no. 1, pp. 68-73, 2019.

[12] Z. P. Song, Y. Cheng, X. X. Tian et al., "Mechanical properties of limestone from Maixi tunnel under hydro-mechanical coupling," Arabian Journal of Geosciences, vol. 13, no. 402, pp. 1-13, 2020.

[13] P. Z. Zhu, H. Jiang, Z. Qin et al., "Static and dynamic loading effects on the stability of a tailings pond under expansion construction," Journal of Jiangxi University of Technology, vol. 40, no. 1, pp. 62-67, 2019.

[14] Y. Cheng, Z. P. Song, J. F. Jin et al., "Experimental study on stress wave attenuation and energy dissipation of sandstone under full deformation condition," Arabian Journal of Geosciences, vol. 12, no. 23, pp. 736-750, 2019.

[15] K. H. Jiang, Z. K. Yue, Z. Zhou et al., "Field test on influence of side-crossing shield tunnel construction on adjacent high speed railway bridge pile foundation," Journal of Jiangxi University of Technology, vol. 39, no. 5, pp. 1-8, 2018.

[16] Z. P. Song, J. C. Mao, X. X. Tian et al., "Optimization analysis of controlled blasting for passing through houses at close range in super-large section tunnels," Shock and Vibration, vol. 2019, Article ID 1941436, 16 pages, 2019.

[17] X. M. Zhou, "Analysis of pit excavation adjacent to metro station in soft ground," Journal of Jiangxi University of Technology, vol. 39, no. 3, pp. 6-11, 2018.

[18] J. Q. Yang, X. H. Jin, W. W. Wu et al., "DLSM simulation analysis on the blasting vibration response of adjacent tunnel in layered rock mass," Journal of Jiangxi University of Technology, vol. 39, no. 3, pp. 12-17, 2018.

[19] P. Ding, Q. F. Yin, Y. J. Liu et al., "Technical study on earth pressure balance shield construction of high cohesive soil stratum," Journal of Jiangxi University of Technology, vol. 39, no. 1, pp. 22-26, 2018.

[20] Y. Cheng, Z. P. Song, J. F. Jin et al., "Waveform characterisation and energy dissipation of stress wave based on modified SHPB tests," Geomechanics and Engineering, vol. 22, no. 2, pp. 187-196, 2020.

[21] Z. P. Song, G. L. Shi, B. Y. Zhao et al., "Study of the stability of tunnel construction based on double-heading advance construction method," Advances in Mechanical Engineering, vol. 12, no. 1, pp. 1-17, 2020.

[22] P. L. Shen, H. B. Zhang, and Z. Z. Yin, "Numerical simulation of long distance overlapped shield tunneling," West-China Exploration Engineering, vol. 15, no. 11, pp. 93-95, 2003.

[23] W. B. Lei, "Construction technology for Wenfu railway Guantouling tunnel under crossing the highway tunnel," Chinese Journal of Underground Space and Engineering, vol. 3, no. 4, pp. 758-764, 2007.

[24] X. Y. Zhao, "Study on the TBM tunnel beneath existing culvert by numerical simulation," Chinese Journal of Underground Space and Engineering, vol. 7, no. 3, pp. 513-517, 2011.

[25] Z. L. Niu, C. P. Liu, L. Zheng et al., "Numerical simulation study on excavation and support of slab tunnel in large section highway," Journal of Xi'an University of Architecture and Technology, vol. 52, no. 3, pp. 376-383, 2020.

[26] H. P. Lai, H. W. Zheng, Q. M. He et al., "Investigation into parameter optimization of existing metro tunnel for shield tunnel closely undercrossing it at small angle in sand stratum," China Journal of Highway and Transport, vol. 31, no. 10, pp. 130-140, 2018.

[27] X. G. Zhang, D. F. Zhang, K. Liu et al., "Influence of the metro undercut excavation tunnel construction on existing railway bridge pile foundation," Journal of Xi'an University of Architecture And Technology (Natural Science Edition), vol. 47, no. 2, pp. 217-223, 2015.

[28] R. K. Huo, P. Y. Zhou, Z. P. Song et al., "Study on the settlement of large-span metro station's baseplate caused by the tunnels newly built beneath it," Advances in Mechanical Engineering, vol. 11, no. 2, pp. 1-13, 2019.

[29] Z. P. Song, Q. Zhang, K. M. Zhao et al., "Optimization study of advanced double-drift tunnel construction based on on-site monitoring and numerical analysis," Journal of Xi'an University of Architecture And Technology (Natural Science Edition), vol. 50, no. 5, pp. 654-661, 2018.

[30] J. B. Wang, Q. Huo, Z. P. Song et al., "Study on adaptability of primary support arch cover method for large-span embedded tunnels in the upper-soft lower-hard stratum," Advances in Mechanical Engineering, vol. 11, no. 1, pp. 1-15, 2019.

[31] P. Lunardi and C. Z. Cassani, "Construction of an underpass at the ravone railway yard in the city of Bologna: aspects of the design and construction," in Progress in Tunneling after 2000, P. Tauscher and A. Colombo, Eds., pp. 319-328, Patron Editore, Bologna, Italy, 2000.

[32] J. S. Sharma, A. M. Hefny, J. Zhao, and C. W. Chan, "Effect of large excavation on deformation of adjacent MRT tunnels," Tunnelling and Underground Space Technology, vol. 16, no. 2, pp. 93-98, 2001.

[33] Z. P. Song, Z. L. Cao, J. B. Wang et al., "Optimal analysis of tunnel construction methods through cross passage from subway shaft," 
Advanced in Civil Engineering, vol. 2018, no. 44, Article ID 5181954, 14 pages, 2018.

[34] Z. L. Niu, Y. Cheng, Y. W. Zhang et al., "A new method for predicting ground settlement induced by pipe jacking construction," Mathematical Problems in Engineering, vol. 2020, Article ID 1681347, 11 pages, 2020.

[35] C. He, Z. X. Su, and D. Y. Zeng, "Influence of metro shield tunneling on existing tunnel directly above," China Civil Engineering Journal, vol. 41, no. 3, pp. 91-98, 2008. 